\title{
The Evolving Landscape of Fungal Diagnostics, Current and Emerging Microbiological Approaches
}

\author{
Zoe Freeman Weiss ${ }^{1,2, *}$, Armando Leon ${ }^{1}$ and Sophia Koo ${ }^{1}$ \\ 1 Brigham and Women's Hospital, Division of Infectious Diseases, Boston, MA 02115, USA; \\ Aleon4@bwh.harvard.edu (A.L.); skoo@bwh.harvard.edu (S.K.) \\ 2 Massachusetts General Hospital, Division of Infectious Diseases, Boston, MA 02115, USA \\ * Correspondence: zfweiss@mgh.harvard.edu
}

Citation: Freeman Weiss, Z.; Leon, A.; Koo, S. The Evolving Landscape of Fungal Diagnostics, Current and Emerging Microbiological Approaches. J. Fungi 2021, 7, 127. https://doi.org/10.3390/jof7020127

Academic Editor: Juergen Prattes Received: 18 December 2020

Accepted: 4 February 2021

Published: 9 February 202

Publisher's Note: MDPI stays neutral with regard to jurisdictional claims in published maps and institutional affiliations.

Copyright: (c) 2021 by the authors. Licensee MDPI, Basel, Switzerland. This article is an open access article distributed under the terms and conditions of the Creative Commons Attribution (CC BY) license (https:// creativecommons.org/licenses/by/ $4.0 /)$.
Abstract: Invasive fungal infections are increasingly recognized in immunocompromised hosts. Current diagnostic techniques are limited by low sensitivity and prolonged turnaround times. We review emerging diagnostic technologies and platforms for diagnosing the clinically invasive disease caused by Candida, Aspergillus, and Mucorales.

Keywords: fungal diagnostics; mycoses; invasive candidiasis; invasive mold infections; invasive aspergillosis; mucormycosis; transplant; immunocompromised host; non-culture diagnostics; culture independent

\section{Introduction}

In recent years, the incidence of invasive fungal infections has increased in parallel with advances in chemotherapies, immunosuppression in solid organ and hematopoietic cell transplantation, and critical care technologies. The diagnosis of invasive fungal disease has traditionally relied on culture, direct microscopy, and histopathology. Conventional culture techniques are frequently insensitive, have prolonged turnaround times (TAT), and may require invasive sampling. An increase in the diversity of pathogenic species makes phenotypic identification challenging, particularly as the number of skilled clinical mycologists declines. Precise species identification is needed given the variability of antifungal drug susceptibility profiles even between closely related organisms. Thus, nonculture-based techniques have gained interest, particularly those with rapid turnaround times to allow for early clinical detection and decision making [1]. Here, we will review the existing diagnostic landscape, including some commercially available assays and platforms, and delve into promising emerging diagnostic techniques for the detection of Candida and the most common invasive mold infections, including Aspergillus and Mucorales.

\section{Candidiasis}

Candida is a commensal opportunistic organism that can become pathogenic in both immunocompetent and immunocompromised hosts. Though Candida is frequently responsible for superficial infections of the mucosal surfaces (such as in esophagitis or vaginitis), patients may present with more serious localized infections including pyelonephritis, endocarditis, or meningitis. Organ-specific disease is often due to hematogenous spread, particularly in the setting of foreign material (prosthetic valves, indwelling catheters, etc.) and impaired host immunity or anatomic abnormality. Immunocompromised patients are at risk for candidemia and deep-seated infection with visceral disease. Hepatosplenic candidiasis (also called chronic disseminated candidiasis) can result in intra-abdominal abscess or peritonitis and may or may not be associated with active candidemia (in some instances invading through the portal vasculature). Invasive candidiasis (IC) refers to active candidemia with or without deep-seated infection or deep-seated infection with or without active candidemia [2]. 
IC is the most common invasive fungal disease (IFD) in health care settings and mortality ranges between 40 and $60 \%$ [3]. Immunosuppressed patients or those with critical illness in ICU settings are at particularly high risk. More than $90 \%$ of invasive candidiasis (IC) is caused by 5 species-Candida albicans, Candida tropicalis, Candida parapsilosis, Candida krusei, and Candida glabrata [4], though there are over 30 species associated with human disease [5]. The distribution of these species varies geographically and there has been increasing detection of non-albicans Candida species, likely in relationship to selection pressure with the ubiquitous use of azoles and echinocandins. Recently, Candida auris has been identified as a major nosocomial pathogen [6]. Species-level identification is crucial given variations in drug susceptibility and virulence [7].

Blood cultures for detecting IC are positive in less than $50 \%$ of hematogenous disease and may be negative in cases of deep-seated infection without candidemia [8]. Cultures can take 1-5 days to show growth, and subsequent subculturing techniques can take an additional 24-72 h for identification. Delays in identification and subculture are in part due to the low number of circulating organisms, usually $<1$ colony forming unit (CFU) per $\mathrm{mL}$ [9], and slower multiplication rates compared to bacteria. Once blood cultures are positive, follow-up pathogen identification techniques are performed by microscopy, selective chromogenic isolation media, or biochemical/enzymatic testing on subcultures [10]. Automated platforms, such as the VITEK 2 system (bioMérieux, Durham, NC, USA), use fluorescence and biochemical features to perform species identification for a wide spectrum of yeasts and perform some antifungal susceptibility testing within $24 \mathrm{~h}$ [11].

Fungal cultures or histopathology from tissue or sterile body fluids are the gold standard for diagnosing IC in the absence of positive blood cultures [12]. Though 100\% specific, a tissue diagnosis typically requires invasive sampling. Limited sensitivity, slow culturing and identification techniques limit early diagnosis [6,7]. Given the morbidity, mortality, and increasing drug resistance associated with IC, much attention has been paid to the earlier identification along with other non-culture-based methods [13].

\subsection{MALDI-TOF MS}

Matrix-assisted laser desorption/ionization time of flight mass spectrometry (MALDITOF MS) platforms are widely used in clinical microbiology laboratories to identify bacteria and have increasingly been applied to yeast identification from positive cultures. A sample colony from a culture plate is placed onto a MALDI-TOF MS target plate and placed in an ionization chamber, generating a mass spectrum based on the mass-to-charge ratios of highly conserved ribosomal proteins, generating signature peaks that are then compared to reference samples within a database. This technique requires no prior knowledge of the organism and can be performed on multiple samples simultaneously, giving results in $<10 \mathrm{~min}[14,15]$. Accurate diagnosis requires adequate availability of reference strains in available, well-curated, and validated databases. Yeast requires some additional sample preparation as compared to bacteria. MALDI-TOF MS is available through multiple commercial platforms, and is now a standard method for identification of a wide spectrum of yeasts. MALDI-TOF MS has been shown to be more reliable in correctly identifying species of Candida (such as C. auris) than conventional techniques that may be prone to mislabeling closely related isolates, though this is dependent on the available spectra libraries [16]. Though identification is made quickly, this technology still depends on positive blood cultures and subsequent subculturing and isolation. Techniques for direct analysis from positive blood cultures have been developed to reduce time to identification but do not perform as well as subcultured samples [15]. Though MALDI-TOF MS has a high capital equipment cost, it is inexpensive to operate, has the potential for complete automation, and requires minimal technical expertise [14,17].

MALDI-TOF MS has also been used to determine antifungal susceptibilities. In 2009, Marinach et al. demonstrated that the minimal profile change concentration (MPCC), or minimum drug concentration needed to detect a change in MALDI-TOF spectra, and MIC were correlated and breakpoints could be established for antifungal susceptibility. This 
work evaluated the spectra changes in Candida albicans after exposure to varying concentrations of fluconazole [18]. The Bruker company developed a commercially available MALDI BioTyper Antibiotic Susceptibility Test Rapid Assay (MBT-ASTRA) (Bruker Daltonics, Bremen, Germany) which includes the detection of antifungal resistance by estimating growth in the presence of antifungal drugs $(6 \mathrm{~h})$ compared to a control setup without an antifungal. It is able to detect strains of $C$. albicans and C. glabrata that are resistant to caspofungin [19], and more recently has been applied to detect non-echinocandin-susceptible $C$. auris isolates [16]. MALDI-TOF susceptibility testing appears promising. However, agreement between conventional testing and MALDI-TOF may vary, thus conventional testing is still required [20]. Additional potential applications include typing to allow for identification of the geographic origins of specific strains to augment epidemiological tracing of Candida outbreaks (for example with Candida auris) [17].

Other promising spectroscopy techniques have been proven experimentally to detect Candida, though have yet to be applied in clinical laboratories and will be combined in a later section on spectroscopy techniques applied to yeasts and/or molds.

\subsection{Antibodies and Antigen Biomarkers}

Serological testing is frequently used to detect evidence of invasive fungal infection in the absence of, or in conjunction with, culture data. Serological tests either detect antigens from an infecting agent or the antibodies formed in the host to those antigens. A number of latex agglutination tests, Western blot techniques, enzyme immunoassays, immunoprecipitation and immunodiffusion assays have been applied over the years to detect fungal antigens or antigen-antibody precipitates.

Candida polysaccharides and metabolites are important targets for serological testing. The 1,3-B-D-glucan (BDG) assay (Fungitell, East Falmouth, MA, USA), which was FDA cleared in 2004, is the most commonly used fungal antigen assay in clinical laboratories. BDG is a chromogenic quantitative enzyme-linked immunosorbent assay (EIA), designed to detect (1-3)- $\beta$-d-glucan polysaccharide cell wall component of Candida and other pathogenic fungi including Aspergillus sp. and Pneumocystis jiroveci. Sensitivity and specificity is widely variable in the literature at approximately $75-80 \%$ and $80 \%$, respectively, for candidemia and $\sim 65 \%$ and $75 \%$, respectively, for intra-abdominal candidiasis [8]. BDG assays tend to be labor intensive and are generally performed in batch testing at reference laboratories [21]. Rapid TAT versions have been developed (see Table 1). The Wako-B-glucan test (Fujifilm Wako Chemicals, Richmond, VA, USA) is currently only commercially available in Europe. Though slightly less sensitive but more specific than Fungitell, its platform allows for multiple or single use, rather than batch testing, and has a TAT of $\sim 120 \mathrm{~min}[22,23]$. Furthermore, positive BDG assays in patients without IC can be seen with Candida or mold colonization, damage to the intestinal wall, hemodialysis, cellulose dressings, enteral nutrition, or mucositis, and should be only used with caution for screening or to guide pre-emptive antifungal therapy in high-risk immunocompromised patients [7]. 
Table 1. Commercially available blood culture-independent diagnostic modalities for detecting Candida sp. IC: invasive candidiasis. IA: intra-abdominal. DS: deep seated.

\begin{tabular}{|c|c|c|c|c|c|c|c|c|}
\hline Test Name & $\begin{array}{c}\text { Example Commercial } \\
\text { Products }\end{array}$ & Sample Source & TAT & Disadvantages & Sensitivity & Specificity & Notes & Citations \\
\hline 1,3- $\beta$-D-glucan (BDG) & $\begin{array}{c}\text { Fungitell, Fungitell STAT } \\
\text { (Associates of Cape Cod, } \\
\text { Inc.) and Fungitec G-MK. } \\
\text { (Seikagaku). } \\
\text { Wako } \beta \text {-glucan (Fuijifilm } \\
\text { Wako Chemicals) }\end{array}$ & Serum & $\begin{array}{c}\text { Fungitell STAT } \\
\text { (qualitative) } 40-60 \mathrm{~min} \\
\text { Fungitell: } 24-72 \mathrm{~h} \\
120 \mathrm{~min}\end{array}$ & $\begin{array}{l}\text { Not specific for Candida } \\
\text { (e.g., can be + with invasive } \\
\text { aspergillosis, fusariosis, } \\
\text { Pneumocystis jirovecii } \\
\text { infection) } \\
\text { High false positives } \\
\text { Often run in reference labs } \\
\text { Lower sensitivity }\end{array}$ & $\begin{array}{l}\text { IC: } 75-80 \% \\
\text { IA/DS: } 56-77 \%\end{array}$ & $\begin{array}{l}\text { IC: } \sim 80 \% \\
\text { IA/DS: } 57-83 \%\end{array}$ & $\begin{array}{l}\text { FDA approved in 2004, } \\
\text { better performance } \\
\text { with two } \\
\text { consecutive results } \\
\text { Available in Europe, } \\
\text { does not require } \\
\text { batch testing }\end{array}$ & {$[8,22,23]$} \\
\hline Candida mannan & $\begin{array}{c}\text { Pastorex Candida } \\
\text { (Bio-Rad) } \\
\text { Platelia Candida Ag Plus } \\
\text { (Bio-Rad) } \\
\end{array}$ & Serum or plasma & $2 \mathrm{~h}$ & $\begin{array}{l}\text { May form immune } \\
\text { complexes and be } \\
\text { rapidly cleared }\end{array}$ & IC: $58 \%$ & IC: $93 \%$ & Available in Europe & [8] \\
\hline $\begin{array}{c}\text { Combined } \\
\text { mannan/antimannan }\end{array}$ & $\begin{array}{l}\text { Platelia Candida Ag-Plus } \\
\text { and Ab-Plus (Bio-Rad) } \\
\text { Serion Mannan Kit } \\
\text { (Serio GmbH) }\end{array}$ & Serum or plasma & $2 \frac{1}{2} \mathrm{~h}$ & $\begin{array}{l}\text { Low sensitivity due to rapid } \\
\text { clearance and complex } \\
\text { formation with antibodies }\end{array}$ & $\begin{array}{l}\text { IC: } 83 \% \\
\text { IA/DS: } 40 \%\end{array}$ & $\begin{array}{c}\text { IC: } 86 \% \\
\text { IA/DS: } 25 \%\end{array}$ & Available in Europe & {$[8,24,25]$} \\
\hline $\begin{array}{c}\text { T2 Candida } \\
\text { nanodiagnostic panel }\end{array}$ & $\begin{array}{l}\text { T2 Candida } \\
\text { (T2 Biosystems) }\end{array}$ & Whole blood & $4.4+/-1 \mathrm{~h}$ & $\begin{array}{l}\text { Identifies limited number of } \\
\text { Candida species (only } 5 \\
\text { most common) } \\
\text { High cost. Needs further } \\
\text { validation in IA/DS }\end{array}$ & $\begin{array}{l}\text { IC: } 91 \% \\
\text { IA/DS: } 33 \%\end{array}$ & $\begin{array}{c}\text { IC: } 94 \% \\
\text { IA/DS: } 93 \%\end{array}$ & FDA approved & {$[26,27]$} \\
\hline $\begin{array}{l}\text { C. albicans germ tube } \\
\text { antibody assays } \\
\text { (CAGTA) }\end{array}$ & $\begin{array}{l}\text { CAGTA; Vircell Kit and } \\
\text { VirClia IgG Monotest }\end{array}$ & Serum & $\sim 3 \mathrm{~h}$ & $\begin{array}{l}\text { Lower sensitivity for } \\
\text { C. tropicalis }\end{array}$ & $\begin{array}{l}\text { IC: } 42-96 \% \\
\text { IA/DS: } 53-73 \%\end{array}$ & $\begin{array}{l}\text { IC: } 54-100 \% \\
\text { IA/DS: } 54-80 \%\end{array}$ & $\begin{array}{l}\text { Not FDA approved } \\
\text { (used in Europe) } \\
\text { Increased accuracy } \\
\text { when combined } \\
\text { with BDG }\end{array}$ & [28] \\
\hline $\begin{array}{l}\text { Candida PCR } \\
\text { performed directly on } \\
\text { clinical specimens }\end{array}$ & $\begin{array}{c}\text { LightCycler. } \\
\text { SeptiFast (Roche } \\
\text { Diagnostics), SepsiTest } \\
\text { (Molzym), } \\
\text { Magicplex system } \\
\text { (Seegene), or VYOO. } \\
\text { (SIRS-Lab), }\end{array}$ & $\begin{array}{l}\text { Whole blood, serum, } \\
\text { plasma }\end{array}$ & $\begin{array}{l}\text { Minutes to hours } \\
\text { (real-time PCR). } \\
\text { Multiplex PCR: 4-12 h }\end{array}$ & $\begin{array}{l}\text { Not standardized or } \\
\text { validated in } \\
\text { multicenter trials. } \\
\text { False negatives (low burden } \\
\text { of fungal cells in blood, } \\
\text { difficulties with sample } \\
\text { preparation and DNA } \\
\text { extraction) and false } \\
\text { positives (similarities with } \\
\text { human DNA, sample } \\
\text { contamination) }\end{array}$ & $\begin{array}{c}\text { IC: } 73-95 \% \\
\text { IA/DS: 86-91\% }\end{array}$ & $\begin{array}{l}\text { IC: } 92-95 \% \\
\text { IA/DS: } 33-97 \%\end{array}$ & $\begin{array}{l}\text { None FDA approved } \\
\text { Variety of DNA targets } \\
\text { including } \\
\text { Candida-specific genes } \\
\text { or broad range } \\
\text { pan-fungal genes }\end{array}$ & {$[24,29]$} \\
\hline
\end{tabular}


Antibody testing for Candida has been employed to detect infection and has the theoretical potential to monitor disease response with titers. Commercially available antibody testing including the combined mannan (a polysaccharide target of the Candida cell wall [24]) and antimannan IgG tests (Platelia Candida Ag-Plus and Ab-Plus, BioRad; Serion Mannan Kit, Serio GmbH, Bio-Rad, Marnes-la-Coquette, France) are used clinically in Europe but are not FDA cleared in the US. Though insensitive alone, their combined sensitivity and specificity is $83 \%$ and $86 \%$, respectively, for candidemia and $40 \%$ and $25 \%$ for intra-abdominal infection [25]. The C. albicans germ tube antibody assays (CAGTA; Vircell Kit and VirClia IgG Monotest (Granada, Spain) detect antibodies to a Candida hyphal protein (Hwp1) using indirect immunofluorescence [28]. This assay has fewer supporting data, and reported sensitivities and specificities are $42-96 \%$ and $54-100 \%$, respectively, for candidemia [8,30]. In one clinical study of ICU patients, use of the CAGTA assay was associated with lower mortality (presumably due to appropriate antifungal administration) and results were not affected by use of antifungal agents or Candida colonization, a limitation of other serological techniques [31,32]. Other antibody tests targeting Candida-specific enzymes, glycoproteins, secreted proteinases, and hyphal elements have been developed, though are not clinically used [33]. Antibody testing is less sensitive in immunocompromised patients and reliably distinguishing between infection and colonization remains a challenge.

Antigen-specific monoclonal and polyclonal antibodies have been proposed as a method of screening for Candida infection, but these antibodies tend to be highly specific for particular epitopes, limiting their scope of detection to isolated Candida strains. Crossreactivity with other fungal species is also a major concern [13]. Recently, a bispecific monoclonal antibody targeted at $\beta$-glucan and MP65, an immunogenic mannoprotein secreted by C. albicans and other Candida species, (MP65/bglu mAb) has been developed in a murine model but has yet to be tested in a clinical setting [34].

A number of human biomarkers have been explored for diagnosing Candida infections and/or distinguishing between colonization and active infection. Interleukin-17, for example, is upregulated in responses to IC and is a potential marker to help distinguish between active infection and colonization, though its upregulation is not specific to IC and clinical application studies are needed [35].

New biomarkers for Candida and other fungal targets may be uncovered by application of investigational immunomic methods in research settings. Serological proteome analysis (SERPA), which uses high-resolution two-dimensional gel electrophoresis with Western blotting and mass spectrometry, has been applied to uncover new biomarkers. Such biomarkers can be used to detect IC, to characterize antibody/antigen patterns that can distinguish between colonization and infection, measure immune response, and identify targets for future vaccine development [36-39]. This technique involves profiling serological responses to peptides from cell surfaces. It favors the most abundant proteins and does not account for different stage and tissue-specific gene expression from cultured cells. Antigenic protein microarray technologies may overcome this limitation and have been applied to more precisely detect differences in IgG responses, profile host humoral responses during colonization and progression to candidemia, and detect antigens associated with drug resistance [36]. Recombinant complementary DNA expression libraries have been used to identify $C$. albicans genes expressed in host cells during active infection and identify virulence factors, and thus could be applied for identification of clinically relevant biomarkers [40]. Evolving antibody and antigen detection techniques can pave the way for the discovery of new clinically relevant biomarkers. Given the profound immunologic derangements in patients at highest risk for IFI, these techniques may be best applied in research settings, drug, and vaccine development.

Lateral flow assay platforms are an attractive option for rapid, affordable, diagnostic antigen testing in dipstick format. These require no technical expertise and are ideal for point of care (POC) applications, particularly in resource limited settings. Fluid (such as urine or blood) is applied to an absorbent surface and flows over a stripe of antibody-coated 
beads allowing for immunochromatographic antigen detection. Commercially available LFDs are already available for the detection of Candida antigens from cervical swabs [41]. LFDs have been developed to detect antibodies against $C$. albicans enolase for detection of invasive disease, though still needs clinical validation [42]. Dual path platform (DPP) devices (Chembio Diagnostic, Medford, NJ, USA), are enhanced immunochromatographic assays with improved sensitivity and multiplex capability. A DPP immunoassay has been developed to detect Candida from cultured cells but clinical application studies are still required [43].

In general, immunoassay techniques offer the possibility of rapid and even point-ofcare diagnostic testing. However, due to concerns for cross-reactivity with other fungal species, low specificity, and reduced reliability in immunosuppressed hosts, these assays have limited clinical application at this time. Biomarkers that can measure host response or help distinguish between colonization and infection could potentially provide both diagnostic and prognostic information.

\subsection{Nucleic Acid Detection}

Nucleic acid detection is a highly sensitive way of detecting the presence of Candida in clinical samples, providing genus- and species-level identification and, in some cases, detection of antifungal resistance genes. In-house and commercially available PCR assays vary significantly in their targets, including Candida-specific genes and highly conserved broad-range pan-fungal sequences, such as the 5.8S, 18S, 28S, ITS1 or ITS2 targets [29]. A 2011 metanalysis by Avni et al. included 54 studies (4694 patients) using various PCR techniques (such as real time, nested, or reverse-transcriptase-PCR) in single or multiplex (multiple simultaneous targets) formats and demonstrated a pooled sensitivity of $95 \%$ and specificity of $92 \%$ for patients with proven or probable invasive candidiasis vs. at-risk controls. Test performance was improved in those studies that used whole blood samples instead of serum or plasma, pan-fungal rRNA or P450 gene targets, primer-specific rather than multiplexed targets, and PCR detection limits of $\leq 10 \mathrm{CFU}$ in vitro. This analysis also demonstrated that in patients with probable or possible IC, PCR had a higher positivity rate than blood cultures ( $85 \%$ vs. $38 \%$ in probable and $67 \%$ vs. $29 \%$ in possible, respectively). Turnaround times ranged from 4 to $12 \mathrm{~h}$. Only 11 of 54 studies documented the presence of antifungal therapy before sampling, which is a notable limitation [29].

Multiplex syndromic panels that include a predefined number of pathogenic targets, often combining common bacterial, viral, or fungal pathogens, are becoming increasingly popular in clinical microbiology labs and can be applied to a number of different clinical samples (blood, CSF, tissue, etc.). A few commercially developed multiplex PCR platforms have been developed to detect Candida or other common yeast species directly from clinical specimens without requiring blood cultures (TAT 4-10 h), including Septifast (Roche Diagnostics, Manheim, Germany, Magicplex (Seegene, Seoul, South Korea) and VYOO ${ }^{\circledR}$ (SIRS-lab, Jena, Germany) [24]. The SepsiTest. (Molzym, Bremen, Germany) is available in Europe and uses universal PCR with Sanger sequencing. Given the generally low prevalence of fungal pathogens in all patients with suspected blood stream infections, the positive predictive value of these assays as a screening strategy is limited.

Multiplex assays that can be run directly from positive blood cultures are becoming more broadly available for commercial use, although they requiring waiting for blood culture positivity. For example, The FilmArray BCID Panel (BioFire Diagnostics and bioMérieux, Salt Lake City, UT, USA), is an FDA-cleared, rapid (TAT = $1 \mathrm{~h}$ ), 43 target (15 fungal, 5 major Candida spp) assay [44]. The ePlex BCID Panel-FP (Genmark, Carlsbad, CA, USA) is commercially available but not FDA-cleared, and detects up to 15 fungal organisms, including 11 Candida spp. TAT is approximately $1.5 \mathrm{~h} \mathrm{[45].} \mathrm{Multiplex} \mathrm{assays}$ have the advantage of being able to detect multiple organisms simultaneously, where cultures may only reveal one dominant pathogen in a polymicrobial infection. Cartridgebased platforms can be performed rapidly and with limited technical expertise. Further development of large-scale parallel amplification techniques with many targets are needed 
to detect a broader range of species [46]. Due to the limited number of targets, these high-cost systems need to be combined with other identification strategies to identify rare pathogens.

DNA microarray platforms have also been developed for Candida detection from positive blood cultures but are not commercially available. Gene-specific probes are attached to a solid substrate and labeled either using fluorescence or radioactive labels. Samples are added to the microarray, allowing for hybridization, and the subsequent fluorescent pattern is detected by microarray readers and amplified [13]. The Prove-it Sepsis platform (Mobidiag, Espoo, Finland) is a rapid broad-range PCR (3-h TAT) and microarray-based assay that detects 80 total bacterial and fungal targets from positive blood cultures with excellent sensitivity and specificity (99\% and 98\% for fungal targets) [47]. This assay has subsequently been discontinued, possibly due to its prolonged turnaround time compared to MALDI-TOF [48]. Application of this technology directly to clinical specimens, without requiring positive cultures, is an area of further potential development.

There are multiple downsides to nucleic acid detection techniques, including lack of standardization in DNA extraction, genetic targets, and clinical samples (whole blood vs. blood fractions). Traditional PCR techniques require strict temperature control, which limits their POC application. Isothermal methods of nucleic acid detection, such as loop mediated isothermal amplification (LAMP), NA sequence-based amplification (NASBA), and rolling circle amplification (RCA) [13], have been used to overcome this obstacle. Recently, LAMP techniques have been applied to POC assays for other pathogens, so may be an attractive option for application for rapid testing in limited resource settings in the future $[49,50]$.

Primer-specific and multiplex platforms can identify either a single target or a predefined diagnostic spectrum of organisms, missing rare or emerging pathogens. DNA detection techniques, while highly sensitive, are unable to distinguish between pathogenic and commensal organisms [46]. False-positive results may occur due to exogenous sample contamination or similarities with human DNA. Assays that depend on positive blood cultures limit their POC application and those that require cell lysis preclude traditional susceptibility testing. Detection of known resistance mutations may be insensitive, as genes conferring resistance are often present in low copy numbers [51]. Interpretation of positive results from molecular testing in the setting of negative blood cultures is challenging and requires subsequent adjudication. Given an increasing reliance on syndromic multiplexed platforms, methodological standardization and validation in multicenter clinical studies are still needed to better define the clinical utility of these technologies.

Given the narrow spectrum of most primer-specific and multiplex assays (that identify just the most common pathogens), open-ended assays that can identify any species as long as their sequences exist within a reference database are attractive. Next-generation sequencing technologies can allow for whole-genome sequencing (WGS) to detect fungal pathogens without prior knowledge of the species in question. WGS could be applied directly to clinical samples. However, these complex techniques require expensive equipment and specialized laboratory skills, and require further clinical studies. The use of next-generation sequencing will be described in later sections $[1,46]$.

\subsection{T2 Candida, MR Technique}

In 2014, the FDA cleared the use of the commercially available T2Candida assay, an automated qualitative nanodiagnostic instrument platform (T2Dx) (T2 Biosystems, Lexington, MA, USA) that readily identifies the five most common Candida species in whole blood samples without requiring blood culture, based on the DIRECT trial [52]. This platform amplifies Candida DNA using a thermostable polymerase and pan-Candida primers targeting ribosomal DNA intervening transcribed spacer (ITS) region 2. Once amplified, the product is then detected by amplicon-induced agglomeration of super magnetic particles and T2 Magnetic Resonance (T2MR) [21,52]. The T2Candida panel has a TAT of $\sim 4 \mathrm{~h}$ and a reported overall sensitivity and specificity of $91.1 \%$ and $99.4 \%$, respectively, for candidemia. 
Of note, the majority of Candida positive samples generating these estimates $(250 / 256)$ were directly inoculated in the lab at varying concentrations rather than clinical samples from patients with candidemia [52]. When tested in only clinical samples (DIRECT2 trial), the sensitivity was similar (89\% in 36 patients at the time of positive blood cultures) [53]. A 2019 meta-analysis of eight studies of T2MR found concordant sensitivity and specificity (91\% and $94 \%$, respectively), though there was significant heterogeneity among studies. [26]. The sensitivity of this test in non-candidemic patients with intra-abdominal candidiasis was much lower at 33\% with preserved specificity in one study of 48 patients [27].

In patients with candidemia, T2MR was noted to frequently remain positive after treatment was initiated, potentially suggesting greater sensitivity than blood cultures in the subset of patients who had received antifungal therapy prior to testing ( $45 \%$ vs. $24 \%$ ) [53]. The follow up STAMP trial validated this observation, showing that the T2MR assay outperformed blood cultures for monitoring the clearance of candidemia [54]. Diagnostic performance might be improved, particularly in non-candidemic patients, by combining T2MR with BDG [27,55]. Recent outcome studies have suggested that the use of T2MR has been associated with earlier antifungal discontinuation [56] but further clinical endpoints are still needed. Due to cellular lysis during isolation, T2MR techniques do not allow for drug resistance and susceptibility testing, a notable limitation. High costs, the need for specialized equipment, and the limited diagnostic spectrum of this technique are additional barriers to broader use. Further studies are needed to evaluate the role of serial sampling, to better characterize the effect of antifungal therapy, and to understand how to interpret and apply discrepant results when blood cultures are negative but the T2 results are positive [21].

\subsection{Immunohistochemistry}

Fluorescence in situ hybridization (FISH) uses nucleic acid probes to identify pathogenspecific ribosomal RNA sequences. There are commercially available peptide nucleic acid fluorescent in situ hybridization assays (PNA-FISH) that come in multiprobe systems and have high sensitivity and specificity for identifying the five most common Candida spp from positive cultures after a period of fungal growth (19-75 h) [57]. Clinical application studies for the FDA-approved Yeast Traffic Light PNA-FISH (OpGen, Woburn, MA USA) demonstrated reduced empiric echinocandin use and cost savings. TAT is $30-90 \mathrm{~min}$. The newer QuickFish (Opgen, Woburn, MA, USA) can identify bacteria or yeasts from positive blood cultures in less than 20 min [58]. Further development of FISH techniques applied directly to blood samples is needed to obviate the need for positive blood cultures [57]. These platforms do not require significant capital equipment costs and have the potential for high throughput testing.

The Accelerate Pheno system is a commercially available and the FDA approved the ID and rapid phenotypic AST platform that detects a wide range of bacterial targets and 2 species of Candida (C. albicans, C. glabrata) from positive blood cultures using FISH for identification and morphokinetic cellular analysis for susceptibility. Subculture is not required; however, the panel for detecting yeast species is limited [59].

\subsection{Microfluidic Devices}

Lab-on-a-chip devices that use microfluidic principles have been developed to detect fungi in the blood stream rapidly and represent a promising technology for rapid point-ofcare testing. Microfluidic techniques separate and concentrate fungal cells directly from blood samples without requiring positive cultures. A number of techniques have been described, including the use of inertial forces [60], ligand-coated beads to capture and isolate cells with magnetic force [61], and fungal-specific antibody-coated channels [62,63]. The microfluidic techniques can be combined with nucleic amplification techniques or other methods of detection, such as mass spectroscopy [13]. Platforms that do not lyse the fungal cell wall can allow for subsequent susceptibility testing [63]. Asghar et al. developed the first immune-based microfluidic device that detected Candida from spiked saline and 
human whole blood [63]. Further development for research and clinical application is still needed.

\subsection{Conclusion}

Diagnosis of candidemia has traditionally relied on culture-based phenotypic, biochemical/enzymatic, and immunologic approaches. Advances in existing technologies, including MALDI-TOF and multiplex PCR platforms, have allowed for accurate species diagnosis from cultures. Given the time delay in waiting for positive cultures, which is often on the order of a few days, culture-independent diagnostics are of increasing importance. Antibody/antigen-based assays, immunohistochemistry, nucleic acid detection techniques, and T2MR are increasingly being used in clinical settings. POC platforms such as LFDs and lab-on-a-chip devices have attractive features and may, in the future, become options for rapid testing for IC.

\section{Diagnosis of Invasive Mold Infections}

Invasive mold infections (IMI) are a major cause of morbidity and mortality in immunocompromised patients. Aspergillus is the most common opportunistic mold, though Mucorales, Fusarium, Scedosporium/Lomentospora/Pseudallescheria, and Paecilomyces/Purpureocillium are increasingly seen in clinical settings, especially in patients receiving mold-active antifungal prophylaxis [64]. In the absence of microbiologic data, the diagnosis is typically made clinically, with consideration of host factors (e.g., solid organ or hematopoietic cell transplantation (HCT), prolonged steroid use or exposure to immunosuppressants that impair T-lymphocyte function), radiographic appearance, and mycological evidence (e.g., antigen detection). The EORTC-MSG consensus guidelines outline specific criteria for categorizing IMI into possible, probable, or proven disease. However, the classification system is designed for research purposes rather than directing clinical management [12]. In practice, patients are frequently treated with empiric antifungal therapies without a definitive diagnosis, which can result in unnecessary exposure to toxic and costly medications or inadequate treatment in the setting of drug resistance.

Making a definitive diagnosis of invasive mold infection requires positive culture from sterile material or histopathology demonstrating hyphal invasion [12]. Biopsy may be infeasible or unsafe due to the location of infection, or risk of bleeding in patients with thrombocytopenia. Cultures are often insensitive, particularly early in the disease course, and slow growth can delay diagnoses for days to weeks. Colony morphology and microscopic identification from culture and histopathology are laborious, require skilled mycologists, and are not practical for the identification of rare species [14].

Ribosomal sequencing for tissue diagnosis is frequently performed on clinical samples, though sensitivity is variable. Immunohistochemistry may be applied to tissue samples to help distinguish between Aspergillus and Mucorales based on their morphological features, without waiting for positive cultures [65]. Proteomic techniques such as MALDITOF are increasingly being adapted to rapidly make a species diagnosis from prepared cultures in culture-positive cases, which comprise the minority of invasive mold infections overall $[66,67]$. In the absence of culture data, fungal markers like BDG and galactomannan, while non-invasive, are limited by poor sensitivity and specificity and do not apply to all species of mold.

Development and clinical validation of diagnostic tests to detect mold infections is often hindered by the relatively low frequency of cases seen at any single institution and the need for an array of different specimens (blood, serum, plasma, BAL fluid, urine, etc.) for validation [30]. Unlike bacteria, working with mold specimens can be technically challenging. They may be unevenly distributed in samples, exist in different forms at various stage of growth, and have hardy cell wall structures that can make nucleic acid extraction difficult [68]. Debate over nomenclature of mold phylogenies also hinders streamlined standardization. In addition to the need for rapid techniques to identify mold 
species from cultures, rapid non-invasive diagnostic tests are needed to detect IMI and ideally, antifungal resistance, to better guide antifungal therapy.

Here we will discuss the current (see Table 2) and emerging diagnostic techniques (see Table 3) applied to diagnosing invasive mold infections, including pan-fungal diagnostic strategies as well as specific techniques emerging for Aspergillus, Mucorales, and other less common molds.

\subsection{Ribosomal Sequencing}

Clinical specimens, including tissue, blood, BAL fluid, and CSF, can be sent to reference laboratories for ribosomal sequencing for species-level identification. Amplification of highly conserved regions of fungal ribosomal RNA including the internal transcribed spacers 1 and 2 (ITS1 and ITS2) and the D1/D2 regions of the 28S rRNA gene, followed by sequencing, can allow for identification of a broad array of fungal species including rare organisms [69]. The sensitivity and specificity of pan-fungal sequencing techniques vary widely depending on the method of DNA extraction, the type and preparation of clinical sample, and whether hyphal forms are visible on histopathology [70-72]. Formalin fixation can reduce assay sensitivity due to DNA degradation (e.g., from $100 \%$ to $90 \%$ in one study [70]). Samples collected from non-sterile sites may reveal non-pathogenic commensal organisms of uncertain clinical significance [73]. The method of sampling is also important, where open resection provides a better diagnostic yield than FNA or core needle biopsy [70]. Most importantly, sensitivity is highest (>90\%) [70] if fungal forms are visualized on histopathology $[70,74]$. Because of this, the EORTC/MSG recommends sequencing from tissue samples only if fungal elements are present [74]. Use of pan-fungal PCR in samples where fungal forms are not visualized on a clinical sample may help to augment a diagnosis if positive, but must fit clinically and cannot be used to exclude disease, particularly in patients receiving anti-mold therapies where assay sensitivity may be further limited [69]. Lack of technical standardization has been addressed by recent attempts to protocolize PCR methods from tissue samples (https://fpcri.eu/, accessed on 1 December 2020).

\subsection{Next-Generation Sequencing}

Next-generation sequencing (NGS), also called high-throughput/massively parallel sequencing, is a non-culture-based technique that allows for the application of both targeted and whole-genome sequencing (WGS). There are a number of available sequencing technologies and data analytic software packages [75]. All human and microbial DNA is extracted from clinical samples (including blood, CSF, BAL fluid, etc.), without a priori knowledge of a particular target. Sequencing is performed using a "shotgun approach," human DNA is removed, and results are compared to existing nucleotide sequences from in pre-formed databases. This can allow for identification of esoteric species, as well as potential resistance mutations, provided the sequences exist in a reference database. TAT is typically $12-24 \mathrm{~h}$ once it has been received by the reference laboratory [76].

NGS techniques enable evolutionary tracing and were used to identify outbreaks of various fungal infections including cases of Exserohilum rostratum meningitis related to contaminated injections [77], Sarocladium kiliense bloodstream infections from contaminated anti-emetic medication [78], and invasive wound mucormycosis [79]. There are a few commercially available NGS platforms that detect cell-free DNA (mcf-DNA-seq) from plasma (Karius, Redwood, CA, USA), DNA and RNA from cerebrospinal fluid (University of California, USA) and respiratory secretions (IDbyDNA, Salt Lake City, UT, USA) to diagnose fungal pathogens (in addition to bacterial and viral pathogens) [75]. A small number of studies have been performed to address the diagnostic utility of this technique.

Small studies have shown good concordance of NGS with biopsy proven IFI [80,81]. One retrospective cohort study of 82 Karius tests ordered for suspected infection (representing 66 patents) in a varied patient population reported a positive impact only $6 / 82$ cases $(7.3 \%)$, a negative impact in 3 cases $(3.7 \%)$, no impact in 71 cases $(86.6 \%)$, and was 
indeterminate in $2(2.4 \%)$ [82]. Thus far, the majority of studies are limited by small sample size, the inclusion of patients with suspected IFI from varied anatomic sites (e.g., lung, skin, sinuses) and lack of a control group. In one recent retrospective case-control study of 114 HCT recipients, overall sensitivity of NGS for proven/probable IFD was 51\%, 31\% for Aspergillus and 79\% for non-Aspergillus IFD. There were two proven IFD cases where Karius testing was positive and both serum and BAL galactomannans were negative, and only one case of Aspergillus detected in a patient with possible IFD. Only one patient with possible IFD had a pathogen detected. Specificity was reported at 95\%. Thus, this diagnostic modality has low to moderate sensitivity but potentially high specificity in patients with proven or probably pulmonary IFD. Sensitivity was improved when combined with GM or when samples were taken within 3 days of a clinical diagnosis. This assay is potentially useful as an adjunctive diagnostic technique in patients with a very high likelihood of proven or probable pulmonary IFD, with slightly better performance in non-Aspergillus IFD, although the assay cost and need for specimen shipping to a central laboratory may be barriers to adoption [83].

There are significant limitations to unbiased NGS techniques. Commercially available assays are typically expensive and though results are typically available within $24 \mathrm{~h}$, TATs may be delayed due to the need to ship samples to specialized laboratories. Capital equipment costs, the need for highly trained laboratory staff, and comprehensive reference databases have been major limitations to adoption of this technique outside highly specialized reference laboratories. Positive results may represent contamination or identify non-pathogenic commensal organisms. Validation for rare species due to need for positive controls can be challenging $[69,76]$. Overall, low sensitivity precludes the use of NGS for stand-alone testing or to rule out infection. NGS may be useful as an adjunctive test in cases where invasive biopsy is contraindicated [84]. With decreasing costs and expanding databases, this technique is likely to be implemented more broadly $[69,76]$. The clinical application and stewardship of NGS sequencing technologies for diagnosing infection still requires clarification.

\subsection{MALDI-TOF MS}

Species-level identification of molds grown in culture is frequently desired in order to guide antifungal choice. MALDI-TOF MS has the advantage of being able to identify a wide spectrum of species from commercial and in-house databases [85]. Application of MALDITOF MS to filamentous fungi has evolved over the past ten years, but time-consuming sample preparation techniques, which can vary between manufacturers, and limitations of spectral databases and available isolate challenge sets have delayed its widespread use. The mechanism of culturing mold isolates and the stage of fungal growth may impact the identification, as different levels of mycelia and spores are present in liquid versus solid media, which have different proteomic fingerprints $[14,66]$. A number of studies have reported identification rates of filamentous fungi ranging between 15\% and 97\%, depending on the platform and database used. There was a notable trend towards using lower species-level cut offs, a $\log$ (score) that refers to the level of similarity between an unknown tested specimen and reference sample [86], to achieve higher detection rates with only marginal increases in false positivity. A score of $\geq 1.7$ rather than the manufacturer recommended cut off of $\geq 2$ has been widely adopted for fungal isolates [14,86] There are a number of commercially available platforms and significant differences between their curated databases, including the range of species included and the nomenclature used for species identification, which can make generalization somewhat challenging [14].

MALDI-TOF MS is a reasonable alternative to conventional microbiological and molecular methods for species identification from positive cultures, though lack of standardized processing techniques and incomplete database spectra are still limiting factors. Additional molecular diagnostic techniques are needed in cases that cannot be identified. 


\subsection{Other Spectroscopy Techniques}

A variety of other spectroscopy techniques have been applied to fungal diagnostics in the research setting and have the potential for both accurate yeast and mold identification, particularly for use on direct clinical samples (rather than subcultured isolates).

Rapid evaporative ionization mass spectrometry (REIMS) performs MS analysis of the metabolites produced by heating up cells to a gas-phase and identifies microbes based on their lipid content. This technique demonstrated $98-100 \%$ accuracy in identifying Candida isolates $[87,88]$. REIMS has been coupled with electrosurgery and is used for immediate intraoperative tissue identification for malignant tumors [89]. Based on these proof of concept studies, its application in fungal identification is a potential area of future exploration. For example, intraoperative identification of invasive mold infections could allow for immediate therapeutic decisions.

Fourier transform infrared (FT-IR) spectroscopy and Raman spectroscopy (RS) [46] use vibrational spectroscopy-based biochemical profiling to detect pathogen species at extremely high resolution. Raman spectroscopy has extremely high specificity for pathogen detection, though enhancement techniques, such as surface-enhanced Raman spectroscopy (SERS) are required to achieve good sensitivity. SERS uses metallic nanostructures to enhance scattering and could be a potentially useful tool for sensitive biomarker detection and can be applied directly to clinical specimens. SERS has been coupled with PCR techniques (e.g., used in the commercially available RenDx Fungiplex ${ }^{\circledR}$, Renishaw Diagnostics assay, Glasgow, UK) for the detection of Candida and Aspergillus, but its clinical utility is not yet well defined $[90,91]$ Interference-enhanced Raman spectroscopy is a slightly less sensitive but more economically feasible technique (easily fabricated substrates and long-term stability of substrates). It has been applied to the diagnosis of aspergillosis via detection of TAFC fungal siderophore (see Section 4.4) from urine samples with a $<3 \mathrm{~h}$ TAT [92].

PCR coupled with electrospray-ionization mass spectrometry (PCR/ESI-MS) is a promising technique for identification of species-specific sequences in specimens containing visible hyphae and has been successfully applied to the detection of Mucorales in one study, though could theoretically be applied to other species. TAT is about $6 \mathrm{~h}$, although implementation is limited by the significant expense and limited availability of this technique [93].

\section{Aspergillus}

Aspergillus is a ubiquitous airborne environmental mold that can cause invasive aspergillosis (IA) in immunosuppressed patients. Patients at risk for Aspergillus infection include those with prolonged neutropenia, solid organ transplantation, HCT, or exposure to steroids or T-lymphocyte immunosuppressants. For pulmonary aspergillosis, the most common manifestation of Aspergillus infection, respiratory cultures, bronchoalveolar lavage (BAL) and lung biopsy are typically performed to obtain cultures. BAL yield is reduced in patients on antifungal therapy or those that have peripheral lesions. Culture is insensitive, can reveal colonization rather than infection, and can sometimes take days to weeks to yield a result [94]. Identification is often further delayed due to the need for sporulation in order to make a phenotypic identification. Fungal elements may be seen with calcofluor white staining. On histopathology, Gomori methenamine silver or periodic acid-Schiff staining are frequently used, though these stains are not specific for Aspergillus [95].

\subsection{Serologies and Biomarkers}

Clinicians currently heavily rely on serum fungal markers including the BDG and galactomannan (GM) to help establish or provide supporting evidence for the diagnosis of invasive aspergillosis in the absence of culture data. BDG and galactomannan are often ordered in parallel in patients with suspected aspergillosis. A wide range of reported sensitivities and specificities have been described in the literature (See Table 2).

BDG, as described previously, has a relatively high negative predictive value for excluding IFI, but is neither sensitive nor specific for Aspergillus spp. The galactomannan 
Platelia Aspergillus EIA/Ag (Bio-Rad, Redmond, WA, USA) assay is a monoclonal Ab immunoassay that detects branched $\beta-1,5$-linked galactofuranose side chains of the $\alpha$ linked mannosyl backbone of the large GM polysaccharide, a component of the Aspergillus cell wall [96]. At an optical density index (ODI) of 0.5 the pooled sensitivity and specificity for proven or probable IA in serum samples is approximately $78 \%$ and $85 \%$, respectively. Sensitivity decreases and specificity increases at higher ODIs. The GM assay is fairly specific for Aspergillus, can be used in serial monitoring to assess treatment response [97,98], and is FDA-cleared for detection in serum and BAL fluid, though it can be found in other bodily fluids (CSF, pleural fluid). Cross-reactivity in patients with histoplasmosis, fusariosis, and talaromycosis can occur [99]. The diagnostic performance of GM is dependent on the optical density cut off used to interpret positivity, the net state of immunosuppression of the host (higher sensitivity in neutropenic patients), and the presence of antifungal therapy [95]. Though this can be performed in hours, batch testing and use of reference laboratories can delay TAT to days, which can limit its use in early clinical decision making. There are a number of alternative biomarker detection kits that have come onto the market but still need proper validation.

Antibody testing for Aspergillus is available, though its application for the diagnosis of IPA is limited, given the weak and variable immune response elicited in neutropenic or immunosuppressed patients. Antibody testing is available for patients with suspected allergic or chronic cavitary aspergillosis, but will not be reviewed here $[100,101]$.

\subsection{Lateral Flow Devices}

Immunochromatographic lateral flow assays for IPA have been developed for POC (TAT 15-30 min), rapid testing. The AspLFD (OLM Diagnostics, Newcastle upon Tyne, UK, and the Aspergillus galactomannan LFA (IMMY) are two such assays, currently available in Europe. The LFD assay uses a JF5 antibody to detect a mannoprotein antigen released in serum and BAL during active fungal growth [102,103]. Like the GM-EIA, the LFA assay targets galactomannan but uses two mABs which may provide greater sensitivity [104]. It has demonstrated good qualitative agreement with GM-EIA [105]. Both assays show better performance in BAL fluid than serum, and among hematology patients as compared to other patient subgroups [104]. In patients with hematological malignancies, sensitivity and specificity of the LFD and LFA from BAL were $78 \%-89 \%$ and $88 \%-100 \%$, respectively [106]. When applied to non-neutropenic/hematologic malignancy patients, sensitivity and specify were $58-69 \%$ and $68-75 \%$ (see Table 2) [107]. Crossreactivity with other fungal infections, including histoplasmosis (similarly to standard GM-EIA testing), has been observed, and is a potential limitation [108]. Anti-mold agents reduce sensitivity [104], thus use in patients on antifungal prophylaxis or treatment may be constrained.

A lateral flow assay using the galactofuranose-specific monoclonal antibody mAb476 was developed for urine POC testing. Sensitivity and specificity were reported at $80 \%$ and $92 \%$, with higher sensitivity $(90.9 \%)$ in hematologic malignancy patients $[108,109]$. LFDs are inexpensive to produce and can provide rapid easy-to-interpret results without the need for specialized equipment or training. Further clinical studies are needed for broader application.

\subsection{Aspergillus PCR-Based Testing}

An array of PCR-based assays have been developed for the clinical diagnosis of IA. The updated 2019 Cochrane review including 29 studies of PCR from whole blood, serum, or plasma, showed a pooled sensitivity of $79.2 \%$ and specificity of $79.6 \%$ for PCR-based testing. For two or more consecutive positive results, sensitivity was lower at $59.6 \%$ and specificity improved to $95.1 \%$ [110]. Based on a 2012 systematic review, BAL-PCR had a reported sensitivity and specificity of $77 \%$ and $94 \%$, respectively [111].

The implementation of PCR testing on serum, whole blood, and BAL fluid into clinical practice was previously limited by lack of standardization of techniques, with 
notable variability in the methods of DNA extraction, primer use, and differences in reference criteria to define a positive result. The European Aspergillus PCR Initiative (EAPCRI) group was formed in 2006 to develop methodological guidelines for technique standardization [112]. White et al. 2015 showed that when comparing EAPRCI noncompliant protocols with compliant ones, sensitivity increased from $85 \%$ to $98 \%$ and specificity from $82 \%$ to $87 \%$ [112]. Based on the performance of these assays and improved standardization, EORTC/MSG incorporated the use of Aspergillus PCR into the diagnosis of probable invasive aspergillosis in September 2020. To meet mycological criteria, patients must have blood (serum, whole blood, or plasma) PCR positivity on two consecutive tests, BAL PCR positivity on two or more tests, or at least one positive test from blood and one from BAL testing [74].

The majority of assays described in the literature were developed in-house, but there are a number of commercial assays now available in a multiplex format that detect Aspergillus sp. and resistance mutations [69], including the most prevalent cyp51A gene mutations associated with azole resistance (R34/L98H and TR46/Y121F/T289A mutations) $[69,94]$. In addition to rapid diagnosis of resistance mutations, PCR amplification allows for the potential to diagnose mixed strains of Aspergillus with both azole-susceptible and -resistant isolates that would not be detected by conventional phenotypical susceptibility testing [113]. Expansion of commercial tests to include probes for additional resistance mutations is needed. Roth et al. reviews the diagnostic performance of commercially available Aspergillus PCR tests, Including the MycAssay Aspergillus ${ }^{\circledR}$ (Myconostica Ltd., Cambridge UK), AsperGenius ${ }^{\circledR}$ (Pathonostics, Maastricht, The Netherlands), among others (see Table 2) [90].

PCR allows for direct detection of Aspergillus DNA in blood, serum, or BAL fluid and has moderate accuracy for screening high risk patients with suspected IA. It has an excellent negative predictive value ( $95 \%$ with either single or serial testing) and improved positive predictive value with serial performance and/or in combination with other biomarkers [110]. Compared to GM, PCR is more sensitive but slightly less specific, while serial positive PCR is less sensitive but more specific. Unlike GM and BDG which are released during active disease, Aspergillus DNA may be detected in the absence of active angio-invasive disease. Though this assay does not distinguish between active disease and colonization, it does provide a potential opportunity for early initiation of either preemptive therapy in those with high clinical suspicion but inconsistent radiographic findings, or antifungal prophylaxis in at-risk individuals $[110,114]$. PCR could be incorporated as part of a screening strategy for ruling out disease, rather than initiating empiric antifungal therapy in high-risk groups [110].

There are still a number of limitations with the use of PCR. The impact of antifungal therapy on test sensitivity is not well defined. False positivity (up to 12\% [115]) due to cross reactivity with other mold species or environmental contamination remains a concern. Though the meta-analyses described include a spectrum of patients, the majority of PCRbased studies have been applied to patients with hematologic malignancies, thus limiting some extrapolation to solid organ transplant patients or other hosts where the burden of disease may be less, and assays potentially less sensitive [102]. 
Table 2. Commercially available non-culture-based testing for Aspergillosis and Mucorales.

\begin{tabular}{|c|c|c|c|c|c|c|c|c|}
\hline Test Name & $\begin{array}{c}\text { Example } \\
\text { Commercial } \\
\text { Product }\end{array}$ & Sample Source & TAT & Disadvantages & Sensitivity & Specificity & Notes & Citations \\
\hline $\begin{array}{l}\text { 1,3- } \beta \text {-D-glucan } \\
\text { (BDG) }\end{array}$ & $\begin{array}{c}\text { Fungitell } \\
\text { (Associates of Cape } \\
\text { Cod, Inc.) and } \\
\text { Fungitec G-MK. } \\
\text { (Seikagaku). }\end{array}$ & Serum & $\begin{array}{l}\text { Fungitell STAT } \\
\text { (qualitative): } \\
\text { 40-60 min } \\
\text { Regular Fungitell: } \\
\text { 24-72 h (d) }\end{array}$ & $\begin{array}{l}\text { Cross-reactive with } \\
\text { other fungi, } \\
\text { False positives } \\
\text { frequent. } \\
\text { Often run in } \\
\text { reference labs. }\end{array}$ & $\begin{array}{c}\text { Fungitell: } 33-100 \% \\
\text { Fungitec: } 67-88 \%\end{array}$ & $\begin{array}{l}\text { Fungitell: } 36-94 \% \\
\text { Fungitec: } 84-85 \%\end{array}$ & FDA approved. & [116] \\
\hline Galactomannan & $\begin{array}{l}\text { Platelia Aspergillus } \\
\text { EIA/Ag (Bio-Rad) }\end{array}$ & $\begin{array}{l}\text { Serum, BAL (also } \\
\text { CSF, pleural fluid) }\end{array}$ & 1-7 days & $\begin{array}{l}\text { Cross-reactive with } \\
\text { other fungi. False } \\
\text { positives frequent. }\end{array}$ & $\begin{array}{l}\text { Neutropenic/heme } \\
\text { malignancy } \\
\text { Serum: } 61-79 \% \\
\text { BALF: } 58-90 \% \\
\text { Non-neutropenic: } \\
\text { Serum: } 38-41 \% \\
\text { BALF: } 65-76 \%\end{array}$ & $\begin{array}{c}\text { Neutropenic/heme } \\
\text { malignancy } \\
\text { Serum: } 81-95 \% \\
\text { BALF: } 84-96 \% \\
\text { Non-neutropenic: } \\
\text { Serum: } 87-89 \% \\
\text { BALF: } 81-90 \%\end{array}$ & $\begin{array}{l}\text { FDA approved. } \\
\text { Serially monitoring } \\
\text { can assess } \\
\text { treatment response. }\end{array}$ & [117-121] \\
\hline Lateral flow devices & $\begin{array}{c}\text { AspLFD (OLM } \\
\text { Diagnostics) and the } \\
\text { Aspergillus } \\
\text { galactomannan LFA } \\
\text { (IMMY) }\end{array}$ & Serum, BAL, urine & $15-30 \mathrm{~min}$ & $\begin{array}{l}\text { Serum LFD requires } \\
\text { additional } \\
\text { preparation } \\
\text { steps/pre-treatment. } \\
\text { Sensitivity decreased } \\
\text { with antifungals. }\end{array}$ & $\begin{array}{c}\text { AspLFD: } \\
\text { Neutropenic/heme } \\
\text { malignancy: } \\
\text { Serum: } 56-68 \% \\
\text { BAL: } 71-89 \% \\
\text { Non-neutropenic: } \\
\text { BAL: } 46-69 \% \\
\text { LFA: } \\
\frac{\text { Neutropenic/heme }}{\text { malignancy: }} \\
89-97 \% \\
\frac{\text { Non-neutropenic: }}{\text { BALF: } 65-69 \%}\end{array}$ & $\begin{array}{c}\text { AspLFD: } \\
\text { Neutropenic/heme } \\
\text { malignancy: } \\
\text { Serum: } 87-90 \% \\
\text { BAL: } 88-100 \% \\
\text { Non-neutropenic: } \\
\text { BAL: } 46-58 \% \\
\text { LFA: } \\
\text { Neutropenic/heme } \\
\text { malignancy: } \\
88-98 \% \\
\text { Non-neutropenic: } \\
\text { BALF: } 62-68 \%\end{array}$ & $\begin{array}{l}\text { Available in Europe. } \\
\text { Urinary GM-like } \\
\text { antigen-based test } \\
\text { also exists but needs } \\
\text { further validation. }\end{array}$ & {$[103-107,109]$} \\
\hline Aspergillus PCR & $\begin{array}{c}\text { MycAssay } \\
\text { Aspergillus } \\
\text { (real-time PCR) } \\
\text { AsperGenius assay } \\
\text { (multiplex } \\
\text { real-time PCR) }\end{array}$ & Serum, BAL & $12-24 \mathrm{~h}$ & $\begin{array}{l}\text { Sensitivity decreased } \\
\text { by antifungal } \\
\text { treatment. Many } \\
\text { commercially } \\
\text { available assays. } \\
\text { Standardization } \\
\text { efforts ongoing. }\end{array}$ & $\begin{array}{l}\text { Serum: } 60-79 \% \\
\text { BALF: } 77 \%\end{array}$ & $\begin{array}{l}\text { Serum: } 80-95 \% \\
\text { BALF: } 94 \%\end{array}$ & $\begin{array}{c}\text { Some detect } \\
\text { azole-resistant } \\
\text { mutations. } \\
\text { Independent } \\
\text { validation still } \\
\text { needed for most. }\end{array}$ & {$[90,110-112]$} \\
\hline Mucorales PCR & $\begin{array}{l}\text { MucorGenius } \\
\text { (Pathonostics) }\end{array}$ & BAL, biopsy fluid & $3 \mathrm{~h}$ & $\begin{array}{c}\text { Small } \\
\text { clinical studies. }\end{array}$ & $90-100 \%$ & $90-99 \%$ & & {$[122,123]$} \\
\hline
\end{tabular}




\subsection{Radiotracers}

The diagnosis of IPA requires chest imaging, though abnormalities on basic chest tomograms (CT) are often non-specific and difficult to distinguish from other forms of invasive mold infections. Combining CT and positron emission tomography (PET) with [18F]fluorodeoxyglucose, a marker of metabolic activity, helps to localize an area of abnormality but does not distinguish between malignancy, infection, or inflammation [124]. A number of radiotracers have been developed to better image IPA and could theoretically be useful as adjunctive diagnostic tools to visualize infected tissue and monitor clinical response to treatment [125].

In preclinical murine experiments with two ${ }^{99 \mathrm{~m}} \mathrm{Tc}$ labeled Aspergillus-specific fungal rRNA-targeted Morpholino oligomers (MORF) probes, researchers observed that probe accumulation is two times higher in infected lungs than non-infected lungs on singlephoton emission tomography (SPECT)/CT imaging. One of the probes (AGEN) was Aspergillus genus specific but had some cross reactivity with $C$. albicans while the other (AFUM) was species specific for A. fumigatus only, limiting its scope of detection [126].

Another imaging technique that has been developed combines microPET/CT with the detection of iron-scavenging siderophores. Siderophores are specific iron-chelating molecules secreted by fungi, which act as virulence factors. A. fumigatus and A. nidulans produce the siderophores triacetylfusarinine $C$ (TAFC) and ferricrocin (FC), which, when combined with ${ }^{68} \mathrm{Ga}$, a radionuclide with complexing properties similar to that of iron, can be visualized on microPET/CT $[127,128]$. This method allows for diagnosis, localization, and potentially determination of severity of diseases by degree of uptake, though its application to other species of Aspergillus is lacking (e.g., A. terreus and A. niger produce other siderophore types [129]. Recent studies using fluorescent dyes highlight the potential for hybrid imaging in localizing infection [130]. The effect of antifungal prophylaxis, the degree of iron overload (competing with radiolabeled siderophores), and observed cross reactivity with other species are potential limitations to test sensitivity and specificity $[125,127,131]$. This modality has also not been well described for the identification of other species of Aspergillus aside from A. fumigatus. Further studies have evaluated the sensitivity of other siderophores [127] and explore the possible use of other radionuclides with longer half-lives for longitudinal monitoring [132].

The use of imaging combined with antibody detection has been well described in cancer diagnostics. The high specificity of $\mathrm{mAbs}$, as previously mentioned, for diagnosing IA makes antibody-guided imaging techniques an attractive and highly specific way to both detect and visualize IA. In a murine model of neutrophil depleted mice infected with Aspergillus, $\left[{ }^{64} \mathrm{Cu}\right] \mathrm{DOTA}-l a b e l e d \mathrm{mAb} \mathrm{mJF5}$, a monoclonal antibody specific to a mannoprotein antigen of Aspergillus sp. released during active fungal growth, was effective in localizing an area of the lung infection with PET/MRI while discriminating between active infection and colonization from other pathologies [124]. Given the long half-life of $\left[{ }^{64} \mathrm{Cu}\right]$ DOTA-mJF5, serial imaging could potentially be applied for monitoring response to antifungal treatment and progression of disease [124]. Immuno-PET MR has a broader diagnostic spectrum for Aspergillus sp. than the above-described techniques. The JF5 has recently been engineered for use in humans with preclinical studies showing enhanced diagnostic performance compared to its murine counterpart, bringing immuno-PET-MR closer to the clinical landscape [133]. The assessment of semi-invasive aspergillosis syndromes (e.g., in patients with COPD or other chronic lung disease) or the detection of extrapulmonary infections are areas of potential exploration [125].

\subsection{Volatile Metabolite Profiles of Aspergillus}

Another non-invasive method of Aspergillus detection utilizes exhaled air for detection of volatile organic compounds (VOCs) released in breath in the setting of IA [134,135]. A proof-of-concept study demonstrated distinct VOC signatures with $100 \%$ sensitivity and $83 \%$ specificity in high-risk hematologic malignancy patients using "electronic nose" technology [134]. In a prospective study of 64 patients with hematologic malignancies, detection 
of specific secondary metabolite volatile organic compounds using thermal desorption/gas chromatography/mass spectrometry ( $\alpha$-trans-bergamotene, $\beta$-trans-bergamotene, a $\beta$ vatirenene-like sesquiterpene, and trans-geranylacetone) had a sensitivity and specificity of $94 \%$ and $93 \%$, respectively, for IA [135]. Volatile metabolite profiles could be useful biomarkers for rapid and inexpensive diagnosis of IFI, but are pending further clinical validation. The relationship between metabolite signature and nodule size, the kinetics of these metabolites with antifungal therapy, and distinguishing between colonization versus infection are all areas of potential exploration [135]. This technology could be applied for the detection of other pathogenic molds and endemic fungi [136].

\section{Mucorales}

Invasive mucormycosis, caused by filamentous fungi of the order Mucorales, is the second most common invasive mold infection after invasive aspergillosis [137]. Mucorales causes significant morbidity and mortality in immunocompromised hosts and in patients with poorly controlled diabetes mellitus and ketoacidosis. Diagnosis is usually made by culture and histopathology and is essential to guide mold active therapy, as several first-line antifungal agents lack therapeutic efficacy against Mucorales. Given the low yield of biopsy and culture, patients are often started on empiric therapy for suspected disease with broad spectrum antifungal therapy that covers both Aspergillus and Mucorales, as distinguishing between these two entities without definitive confirmation can be challenging. Molecular methods are typically employed for species identification and detection when cultures are negative and can detect potentially mixed infections [138]. There are no commercially available serological tests, though this is an area of active development.

\subsection{Mucorales-Specific PCR}

In addition to PCR from tissue biopsy samples, serum and BAL PCR assays have been used to detect Mucorales from clinical samples. BAL PCR may be a useful adjunctive test to allow for earlier initiation of antifungal therapy and detection in culture-negative BAL samples [139]. One study of BAL fluid from 374 immunosuppressed patients with pneumonia used a combined approach of three qPCR assays on BAL fluid. A total of 24 patients had a positive BALPCR; 23/24 met radiologic criteria for IMI, of which 7 had proven and 3 had probable mucormycosis, 5 had other fungal infections, and 8 had possible IFD. Sensitivity and specificity for probable or biopsy-proven pulmonary mucormycosis was $100 \%$ and $97 \%$, respectively. Only $2 / 24$ PCR positive samples had concordant positive cultures [139]. PCR combined with high-resolution melt analysis (PCR/HRMA) has also been described, and showed a sensitivity and specificity of $100 \%$ and $93 \%$ in one study of 99 BAL samples (9 of which were positive) [122]. MucorGenius (Pathonostics, Maastricht, The Netherlands), is a non-FDA approved semi-quantitative PCR assay that targets $28 \mathrm{~S}$ rRNA in BAL and biopsy samples and can be run in parallel with AsperGenius, with a TAT of $3 \mathrm{~h}[123,140]$.

Non-invasive techniques to detect Mucorales PCR from plasma, serum, or urine are desired to avoid biopsy and even BAL in critically ill patients unable to tolerate these procedures. qPCR using genera-specific, broad-range, or multiplex PCR from serum has been described as successful in detecting infection as early as up to 28 days prior to mycological diagnosis [138,139,141,142] and up to 3 days earlier than classic radiographic findings [143]. Millon et al. reported a sensitivity between $81 \%$ and $92 \%$ when combining 3 genera-specific real-time qPCR assays, with notably higher sensitivities using larger sample volumes $(1 \mathrm{~mL})$ [141]. Sensitivity of PCR is reduced in those receiving antifungal therapy, a notable limitation $[141,143]$. Persistent DNA detection despite antifungal initiation was associated with higher mortality, suggesting a possible application for serial sampling in prognostication or treatment monitoring [141]. PCR techniques could be considered for screening high risk patients [141] and efforts to standardize PCR techniques will allow for broader application in the future [138]. 


\subsection{Other Biomarkers}

The detection of mold-reactive CD154+ cells has been suggested as a non-invasive (TAT $\sim 24 \mathrm{~h}$ ) way to detect invasive Mucorales. Mucorales-specific T cells were identified via enzyme-linked immunospot (ELISpot) and were found to be reactive only in patients with proven invasive mucormycosis (IM). These CD4+ or CD8+ cells produced IL-4, IL10 (Th2) ${ }^{4}$, IFN- $\gamma$, and IL-17, but only during the course of active infection, not detected before or after [144,145]. Steinbach et al. quantified mold-reactive CD4/CD69/CD154+ lymphocytes with flow cytometry and found a sensitivity of $100 \%$ and a specificity of $81 \%$ for Mucorales infection in a cohort of 115 at risk patients (4 with proven, 3 with probable, and 44 with possible IMI), with a TAT of about $24 \mathrm{~h}$. Though only a small number of patients with Mucorales were included, this test could theoretically be used to rule out disease or make an earlier diagnosis prior to disease manifestation/progression. Patients with T cell counts $<4500$ were excluded, thus limiting extrapolation to those with severe bone marrow suppression and T-cell dysfunction. Given the underlying immune deficiencies in patients at risk for mucormycosis, this is a significant limitation to this approach [146].

Burnham-Marusich et al. developed a pan-fungal monoclonal antibody, 2DA6, that reacts with purified mannans of different fungi, including Rhizopus, Mucor, and Aspergillus and can be detected using enzyme-linked immunosorbent assay (ELISA). A lateral flow format for this test has been developed. Such an assay may be useful in addition to the BDG assay, which is typically negative in Rhizopus and Mucor infections [147]. Human validation studies are still needed.

Using a method of screening genomic libraries called signal sequence trap by retrovirusmediated expression (SST-REX), Sato et al. isolated a Rhizopus-specific antigen (RSA) and developed a corresponding ELISA assay, which is still pending clinical validation. SST-REX has traditionally been applied for the detection of biomarkers in malignancies, and has the potential for application to fungal diagnostics [148].

\section{Conclusions}

With the growing threat of invasive fungal infections and concurrent rise in antifungal resistance, new technologies have emerged for rapid species identification and earlier detection of IFD. Advancements in proteomics and molecular techniques have allowed for highly discriminatory species identification. Non-culture-based methods including enhanced imaging modalities, T2 magnetic resonance assays, multiplex panels, NGS metagenomic sequencing, volatile metabolites, and new immunologic biomarkers could overcome the prolonged turnaround times and limited sensitivity of traditional techniques, while potentially obviating the need for invasive sampling. Lateral flow devices, microfluidics, and microarrays are promising platforms for clinical integration.

Further studies are needed to define the performance characteristics of many of these technologies and their clinical impact on patient outcomes. When the gold standard is relatively insensitive, defining the precise performance characteristics of non-culture-based techniques is challenging. A rational approach to adjudicating results must be applied where an assay that theoretically outperforms the gold standard produces discordant results. Even highly sensitive and specific tests have limited positive predictive value when applied to patient populations at low risk of IFD, so implementation of new technologies as a part of "screening" algorithms must be performed judiciously. Considerations of capital equipment costs and laboratory staff training must be weighed against the potential cost-saving benefits of earlier diagnosis, given the high costs associated with IFD and IFD-related hospitalizations. 


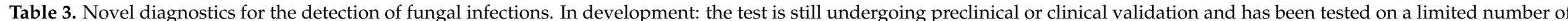
samples. Research only: can be performed in specialized laboratories but is not commercially available or FDA-approved yet.

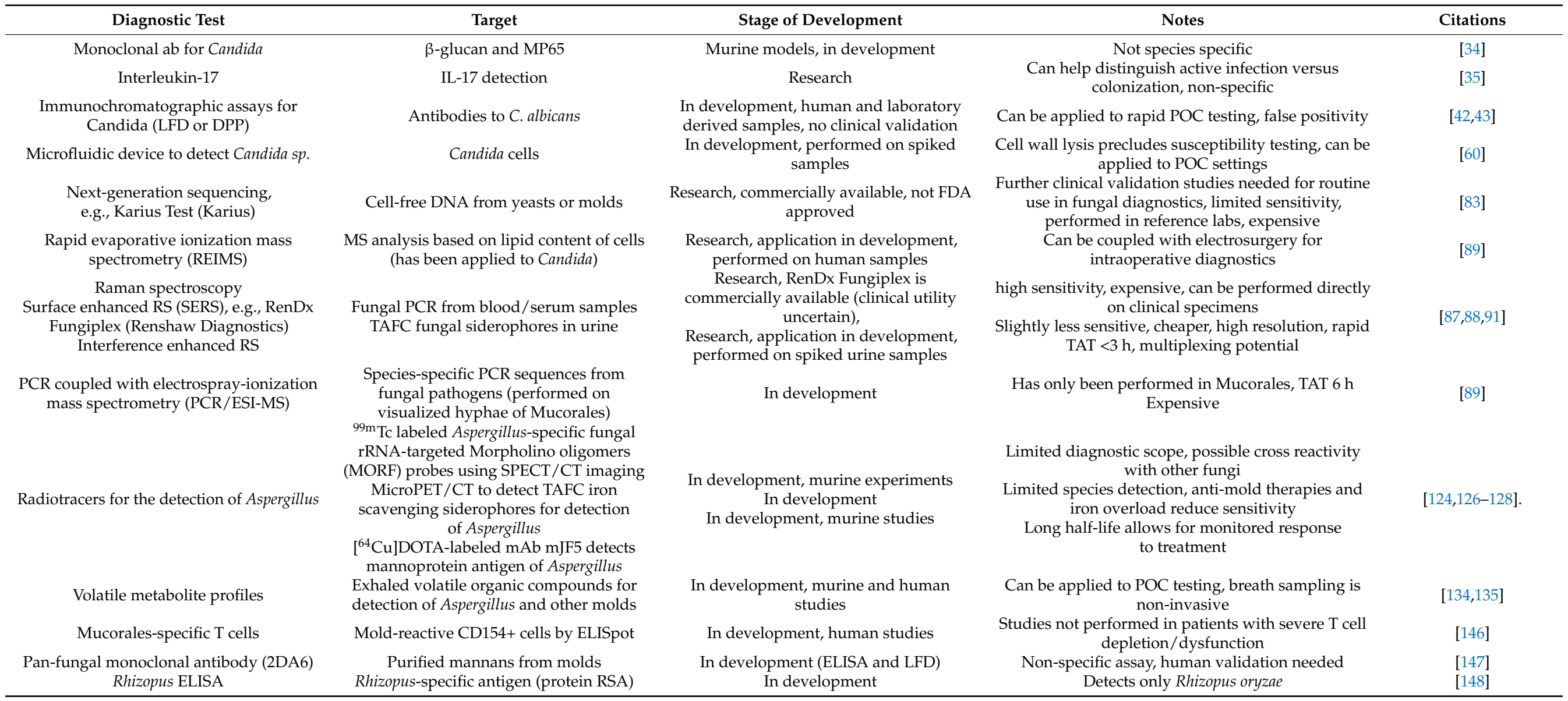


Author Contributions: Conceptualization, Z.F.W., writing—original draft preparation, Z.F.W., A.L.; writing-review and editing, Z.F.W., A.L., S.K., funding acquisition, S.K. All authors have read and agreed to the published version of the manuscript.

Funding: S.K. is supported by NIH R21 AI133330, R21 AI130669, R01 AI138999, and R44 AI141264.

Institutional Review Board Statement: IRB approval was not required for this study.

Informed Consent Statement: Informed consent not applicable.

Data Availability Statement: Data sharing not applicable.

Conflicts of Interest: S.K. has potentially relevant conflict of interest, including research funding from FUJIFILM Wako Diagnostics Corporation and Merck, and consulting for Merck.

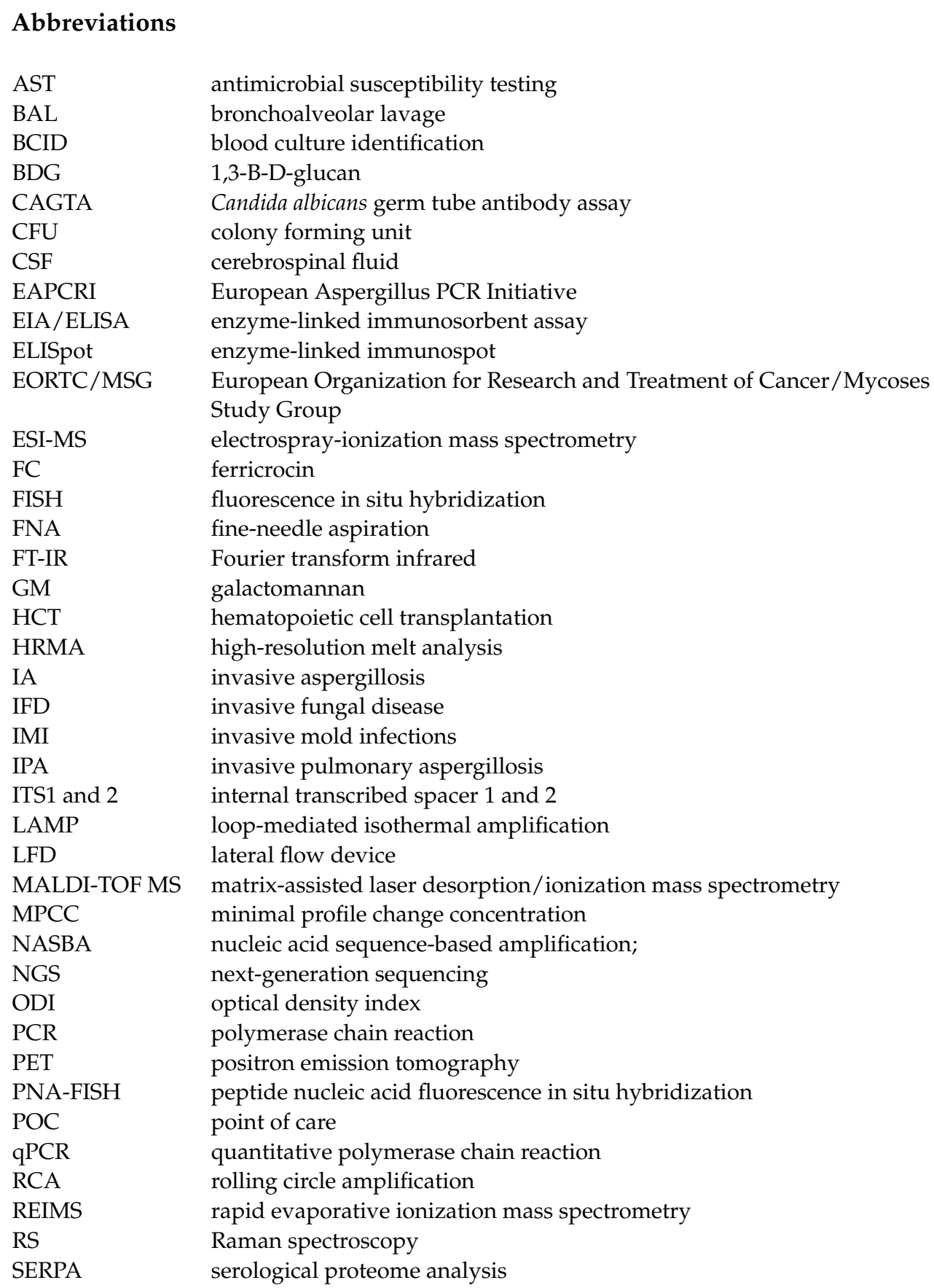


SERS surface-enhanced Raman spectroscopy

SPECT single-photon emission computerized tomography

SST-REX signal sequence trap by retrovirus-mediated expression

TAFC Triacetylfusarinine $\mathrm{C}$

TAT turnaround time

VOC volatile organic compound

WGS whole-genome sequencing

\section{References}

1. Kozel, T.R.; Wickes, B. Fungal Diagnostics. Cold Spring Harb. Perspect. Med. 2014, 4, a019299. [CrossRef] [PubMed]

2. Pappas, P.G.; Kauffman, C.A.; Andes, D.R.; Clancy, C.J.; Marr, K.A.; Ostrosky-Zeichner, L.; Reboli, A.C.; Schuster, M.G.; Vazquez, J.A.; Walsh, T.J.; et al. Clinical Practice Guideline for the Management of Candidiasis: 2016 Update by the Infectious Diseases Society of America. Clin. Infect. Dis. 2016, 62, e1-e50. [CrossRef]

3. Bassetti, M.; Righi, E.; Montravers, P.; Cornely, O.A. What has changed in the treatment of invasive candidiasis? A look at the past 10 years and ahead. J. Antimicrob. Chemother. 2018, 73, i14-i25. [CrossRef] [PubMed]

4. Pfaller, M.A.; Diekema, D.J.; Gibbs, D.L.; Newell, V.A.; Ellis, D.J.; Tullio, V.; Rodloff, A.C.; Fu, W.; Ling, T.A.; The Global Antifungal Surveillance Group. Results from the ARTEMIS DISK Global Antifungal Surveillance Study, 1997 to 2007: A 10.5-Year Analysis of Susceptibilities of Candida Species to Fluconazole and Voriconazole as Determined by CLSI Standardized Disk Diffusion. J. Clin. Microbiol. 2010, 48, 1366-1377.

5. Papon, N.; Courdavault, V.; Clastre, M.; Bennett, R.J. Emerging and Emerged Pathogenic Candida Species: Beyond the Candida albicans Paradigm. PLoS Pathog. 2013, 9, e1003550. [CrossRef] [PubMed]

6. Pappas, P.G.; Lionakis, M.S.; Arendrup, M.C.; Ostrosky-Zeichner, L.; Kullberg, B.J. Invasive Candidiasis. Nat. Rev. Dis. Primers 2018, 4, 18026. [CrossRef]

7. Clancy, C.J.; Nguyen, M.H. Finding the "Missing 50\%" of Invasive Candidiasis: How Nonculture Diagnostics Will Improve Understanding of Disease Spectrum and Transform Patient Care. Clin. Infect. Dis. 2013, 56, 1284-1292. [CrossRef]

8. Clancy, C.J.; Nguyen, M.H. Non-Culture Diagnostics for Invasive Candidiasis: Promise and Unintended Consequences. J. Fungi 2018, 4, 27. [CrossRef]

9. Pfeiffer, C.D.; Samsa, G.P.; Schell, W.A.; Reller, L.B.; Perfect, J.R.; Alexander, B.D. Quantitation of Candida CFU in Initial Positive Blood Cultures. J. Clin. Microbiol. 2011, 49, 2879-2883. [CrossRef]

10. Freydiere, A.M.; Guinet, R.; Boiron, P. Yeast Identification in the Clinical Microbiology Laboratory: Phenotypical Methods. Med. Mycol. 2001, 39, 9-33. [CrossRef]

11. Graf, B.; Adam, T.; Zill, E.; Gobel, U.B. Evaluation of the Vitek 2 System for Rapid Identification of Yeasts and Yeast-Like Organisms. J. Clin. Microbiol. 2000, 38, 1782-1785. [CrossRef]

12. De Pauw, B.; Walsh, T.J.; Donnelly, J.P.; Stevens, D.A.; Edwards, J.E.; Calandra, T.; Pappas, P.G.; Maertens, J.; Lortholary, O.; Kauffman, C.A.; et al. Revised Definitions of Invasive Fungal Disease from the European Organization for Research and Treatment of Cancer/Invasive Fungal Infections Cooperative Group and the National Institute of Allergy and Infectious Diseases Mycoses Study Group (Eortc/Msg) Consensus Group. Clin. Infect. Dis. 2008, 46, 1813-1821.

13. Safavieh, M.; Coarsey, C.; Esiobu, N.; Memic, A.; Vyas, J.M.; Shafiee, H.; Asghar, W. Advances in Candida Detection Platforms for Clinical and Point-of-Care Applications. Crit. Rev. Biotechnol. 2017, 37, 441-458. [CrossRef]

14. Patel, R. A Moldy Application of Maldi: Maldi-Tof Mass Spectrometry for Fungal Identification. J. Fungi 2019, 5, 4. [CrossRef]

15. Patel, R. Matrix-Assisted Laser Desorption Ionization-Time of Flight Mass Spectrometry in Clinical Microbiology. Clin. Infect. Dis. 2013, 57, 564-572. [CrossRef] [PubMed]

16. Vatanshenassan, M.; Boekhout, T.; Meis, J.F.; Berman, J.; Chowdhary, A.; Ben-Ami, R.; Sparbier, K.; Kostrzewa, M. Candida auris Identification and Rapid Antifungal Susceptibility Testing Against Echinocandins by MALDI-TOF MS. Front. Cell. Infect. Dressemicrobiol. 2019, 9, 20. [CrossRef] [PubMed]

17. Delavy, M.; Dos Santos, A.R.; Heiman, C.M.; Coste, A.T. Investigating Antifungal Susceptibility in Candida Species With MALDI-TOF MS-Based Assays. Front. Cell. Infect. Microbiol. 2019, 9, 19. [CrossRef] [PubMed]

18. Marinach, C.; Alanio, A.; Palous, M.; Kwasek, S.; Fekkar, A.; Brossas, J.Y.; Brun, S.; Snounou, G.; Hennequin, C.; Sanglard, D.; et al. Maldi-Tof Ms-Based Drug Susceptibility Testing of Pathogens: The Example of Candida albicans and Fluconazole. Proteomics 2009, 9, 4627-4631. [CrossRef]

19. Vatanshenassan, M.; Boekhout, T.; Lass-Flörl, C.; Lackner, M.; Schubert, S.; Kostrzewa, M.; Sparbier, K. Proof of Concept for MBT ASTRA, a Rapid Matrix-Assisted Laser Desorption Ionization-Time of Flight Mass Spectrometry (MALDI-TOF MS)-Based Method To Detect Caspofungin Resistance in Candida albicans and Candida glabrata. J. Clin. Microbiol. 2018, 56, e00420-18. [CrossRef] [PubMed]

20. Delavy, M.; Cerutti, L.; Croxatto, A.; Prod'Hom, G.; Sanglard, D.; Greub, G.; Coste, A.T. Machine Learning Approach for Candida albicans Fluconazole Resistance Detection Using Matrix-Assisted Laser Desorption/Ionization Time-of-Flight Mass Spectrometry. Front. Microbiol. 2020, 10, 3000. [CrossRef]

21. Clancy, C.J.; Nguyen, M.H. Diagnosing Invasive Candidiasis. J. Clin. Microbiol. 2018, 56, e01909-17. [CrossRef] [PubMed] 
22. Friedrich, R.; Rappold, E.; Bogdan, C.; Held, J. Comparative Analysis of the Wako Beta-Glucan Test and the Fungitell Assay for Diagnosis of Candidemia and Pneumocystis Jirovecii Pneumonia. J. Clin. Microbiol. 2018, 56. [CrossRef]

23. De Carolis, E.; Marchionni, F.; Torelli, R.; Angela, M.G.; Pagano, L.; Murri, R.; De Pascale, G.; De Angelis, G.; Sanguinetti, M.; Posteraro, B. Comparative Performance Evaluation of Wako Beta-Glucan Test and Fungitell Assay for the Diagnosis of Invasive Fungal Diseases. PLoS ONE 2020, 15, e0236095. [CrossRef]

24. Pitarch, A.; Nombela, C.; Gil, C. Diagnosis of Invasive Candidiasis: From Gold Standard Methods to Promising Leading-Edge Technologies. Curr. Top. Med. Chem. 2018, 18, 1375-1392. [CrossRef] [PubMed]

25. Mikulska, M.; Calandra, T.; Sanguinetti, M.; Poulain, D.; Viscoli, C. The Use of Mannan Antigen and Anti-Mannan Antibodies in the Diagnosis of Invasive Candidiasis: Recommendations from the Third European Conference on Infections in Leukemia. Crit. Care 2010, 14, R222. [CrossRef]

26. Tang, D.L.; Chen, X.; Zhu, C.G.; Li, Z.W.; Xia, Y.; Guo, X.G. Pooled Analysis of T2 Candida for Rapid Diagnosis of Candidiasis. Bmc Infect. Dis. 2019, 19, 798. [CrossRef]

27. Lamoth, F.; Clancy, C.J.; Tissot, F.; Squires, K.; Eggimann, P.; Flückiger, U.; Siegemund, M.; Orasch, C.; Zimmerli, S.; Calandra, T.; et al. Performance of the T2Candida Panel for the Diagnosis of Intra-abdominal Candidiasis. Open Forum Infect. Dis. 2020, 7, ofaa075. [CrossRef]

28. Martínez-Jiménez, M.C.; Muñoz, P.; Guinea, J.; Valerio, M.; Alonso, R.; Escribano, P.; Bouza, E. Potential role of Candida albicans germ tube antibody in the diagnosis of deep-seated candidemia. Med. Mycol. 2014, 52, 270-275. [CrossRef]

29. Avni, T.; Leibovici, L.; Paul, M. PCR Diagnosis of Invasive Candidiasis: Systematic Review and Meta-Analysis. J. Clin. Microbiol. 2010, 49, 665-670. [CrossRef]

30. Arvanitis, M.; Anagnostou, T.; Fuchs, B.B.; Caliendo, A.M.; Mylonakis, E. Molecular and Nonmolecular Diagnostic Methods for Invasive Fungal Infections. Clin. Microbiol. Rev. 2014, 27, 490-526. [CrossRef]

31. Pemán, J.; The Study Group Candida Albicans Germ Tube Antibody Detection in Critically Ill Patients (CAGTAUCI); Zaragoza, R.; Quindós, G.; Alkorta, M.; Cuétara, M.S.; Camarena, J.J.; Ramírez, P.; Giménez, M.J.; Mazuelos, E.M.; et al. Clinical factors associated with a Candida albicansGerm Tube Antibody positive test in Intensive Care Unit patients. BMC Infect. Dis. 2011, 11,60 .

32. Zaragoza, R.; Pemán, J.; Quindós, G.; Iruretagoyena, J.; Cuétara, M.S.; Ramírez, P.; Gómez, M.D.; Camarena, J.; Viudes, A.; Pontón, J.; et al. Clinical significance of the detection of Candida albicans germ tube-specific antibodies in critically ill patients. Clin. Microbiol. Infect. 2009, 15, 592-595. [CrossRef]

33. Laín, A.; Elguezabal, N.; Amutio, E.; De Larrinoa, I.F.; Moragues, M.D.; Pontón, J. Use of Recombinant Antigens for the Diagnosis of Invasive Candidiasis. Clin. Dev. Immunol. 2008, 2008, 1-7. [CrossRef]

34. Zito, A.; Bromuro, C.; Mandili, G.; Chiani, P.; Horenstein, A.L.; Malavasi, F.; Cauda, R.; Cassone, A.; Torosantucci, A. A Murine, Bispecific Monoclonal Antibody Simultaneously Recognizing Beta-Glucan and Mp65 Determinants in Candida Species. PLoS ONE 2016, 11, e0148714. [CrossRef]

35. Krause, R.; Zollner-Schwetz, I.; Salzer, H.J.F.; Valentin, T.; Rabensteiner, J.; Prüller, F.; Raggam, R.; Meinitzer, A.; Prattes, J.; Rinner, B.; et al. Elevated Levels of Interleukin 17A and Kynurenine in Candidemic Patients, Compared with Levels in Noncandidemic Patients in the Intensive Care Unit and Those in Healthy Controls. J. Infect. Dis. 2014, 211, 445-451. [CrossRef]

36. Mochon, A.B.; Jin, T.; Kayala, M.A.; Wingard, J.R.; Clancy, C.J.; Nguyen, M.H.; Felgner, P.; Baldi, P.; Liu, H. Serological Profiling of a Candida albicans Protein Microarray Reveals Permanent Host-Pathogen Interplay and Stage-Specific Responses During Candidemia. PLoS Pathog. 2010, 6, e1000827. [CrossRef]

37. Pitarch, A.; Jiménez, A.; Nombela, C.; Gil, C. Serological proteome analysis to identify systemic candidiasis patients in the intensive care unit: Analytical, diagnostic and prognostic validation of anti-Candida enolase antibodies on quantitative clinical platforms. Proteom. Clin. Appl. 2008, 2, 596-618. [CrossRef] [PubMed]

38. Pitarch, A.; Nombela, C.; Gil, C. Top-down characterization data on the speciation of the Candida albicans immunome in candidemia. Data Brief 2016, 6, 257-261. [CrossRef] [PubMed]

39. Pitarch, A.; Jiménez, A.; Nombela, C.; Gil, C. Decoding Serological Response to Candida Cell Wall Immunome into Novel Diagnostic, Prognostic, and Therapeutic Candidates for Systemic Candidiasis by Proteomic and Bioinformatic Analyses. Mol. Cell. Proteom. 2006, 5, 79-96. [CrossRef]

40. Clancy, C.J.; Cheng, S.; Nguyen, M.H. Antibody-Based Strategy to Identify Candida albicans Genes Expressed During Infections. In Toxicity Assessment; Springer: Berlin, Germany, 2009; Volume 470, pp. 169-185.

41. Dan, M.; Leshem, Y.; Yeshaya, A. Performance of a rapid yeast test in detecting Candida spp. in the vagina. Diagn. Microbiol. Infect. Dis. 2010, 67, 52-55. [CrossRef]

42. He, Z.-X.; Shi, L.-C.; Ran, X.-Y.; Li, W.; Wang, X.-L.; Wang, F. Development of a Lateral Flow Immunoassay for the Rapid Diagnosis of Invasive Candidiasis. Front. Microbiol. 2016, 7, 1451. [CrossRef]

43. Gunasekera, M.; Narine, M.; Ashton, M.; Esfandiari, J. Development of a Dual Path Platform (Dpp(R)) Immunoassay for Rapid Detection of Candida albicans in Human Whole Blood and Serum. J. Immunol. Methods 2015, 424, 7-13. [CrossRef]

44. Salimnia, H.; Fairfax, M.; Lephart, P.R.; Schreckenberger, P.; DesJarlais, S.M.; Johnson, J.K.; Robinson, G.; Carroll, K.C.; Greer, A.A.; Morgan, M.; et al. Evaluation of the Film Array Blood Culture Identification Panel: Results of a Multicenter Controlled Trial. J. Clin. Microbiol. 2016, 54, 687-698. [CrossRef] 
45. Maubon, D.; Dard, C.; Garnaud, C.; Cornet, M. Profile of Genmark's Eplex(R) Blood Culture Identification Fungal Pathogen Panel. Expert Rev. Mol. Diagn. 2018, 18, 119-132. [CrossRef]

46. OPATHY Consortium; Arastehfar, A.; Boekhout, T.; Butler, G.; De Cesare, G.B.; Dolk, E.; Gabaldóln, T.; Hafez, A.; Hube, B.; Hagen, F.; et al. Recent trends in molecular diagnostics of yeast infections: From PCR to NGS. Fems Microbiol. Rev. 2019, 43, 517-547.

47. Aittakorpi, A.; Pentti, K.; Koukila-Kähkölä, P.; Vaara, M.; Petrou, M.; Gant, V.; Mäki, M. Accurate and Rapid Identification of Candida Spp. Frequently Associated with Fungemia by Using Pcr and the Microarray-Based Prove-It Sepsis Assay. J. Clin. Microbiol. 2012, 50, 3635-3640. [CrossRef] [PubMed]

48. Dubourg, G.; Raoult, D.; Fenollar, F. Emerging methodologies for pathogen identification in bloodstream infections: An update. Expert Rev. Mol. Diagn. 2019, 19, 161-173. [CrossRef] [PubMed]

49. Njiru, Z.K. Loop-Mediated Isothermal Amplification Technology: Towards Point of Care Diagnostics. PLoS Negl. Trop. Dis. 2012, 6, e1572. [CrossRef]

50. Fallahi, S.; Babaei, M.; Rostami, A.; Mirahmadi, H.; Arab-Mazar, Z.; Sepahvand, A. Diagnosis of Candida Albicans: Conventional Diagnostic Methods Compared to the Loop-Mediated Isothermal Amplification (Lamp) Assay. Arch. Microbiol. 2020, 202, 275-282. [CrossRef]

51. Perlin, D.S.; Wiederhold, N.P. Culture-Independent Molecular Methods for Detection of Antifungal Resistance Mechanisms and Fungal Identification. J. Infect. Dis. 2017, 216, S458-S465. [CrossRef] [PubMed]

52. Mylonakis, E.; Clancy, C.J.; Ostrosky-Zeichner, L.; Garey, K.W.; Alangaden, G.J.; Vazquez, J.A.; Groeger, J.S.; Judson, M.A.; Vinagre, Y.-M.; Heard, S.O.; et al. T2 Magnetic Resonance Assay for the Rapid Diagnosis of Candidemia in Whole Blood: A Clinical Trial. Clin. Infect. Dis. 2015, 60, 892-899. [CrossRef]

53. Clancy, C.J.; Pappas, P.G.; Vazquez, J.; Judson, M.A.; Kontoyiannis, D.P.; Thompson, G.R., III; Garey, K.W.; Reboli, A.; Greenberg, R.N.; Apewokin, S.; et al. Detecting Infections Rapidly and Easily for Candidemia Trial, Part 2 (Direct2): A Prospective, Multicenter Study of the T2candida Panel. Clin. Infect. Dis. 2018, 66, 1678-1686. [CrossRef]

54. Mylonakis, E.; Zacharioudakis, I.M.; Clancy, C.J.; Nguyen, M.H.; Pappas, P.G. Efficacy of T2 Magnetic Resonance Assay in Monitoring Candidemia after Initiation of Antifungal Therapy: The Serial Therapeutic and Antifungal Monitoring Protocol (STAMP) Trial. J. Clin. Microbiol. 2018, 56. [CrossRef] [PubMed]

55. Arendrup, M.C.; Andersen, J.S.; Holten, M.K.; Krarup, K.B.; Reiter, N.; Schierbeck, J.; Helleberg, M. Diagnostic Performance of T2Candida Among ICU Patients with Risk Factors for Invasive Candidiasis. Open Forum Infect. Dis. 2019, 6, ofz136. [CrossRef] [PubMed]

56. Gill, C.M.; Kenney, R.M.; Hencken, L.; Mlynarek, M.E.; Alangaden, G.J.; Samuel, L.P.; Davis, S.L. T2 Candida versus beta-D-glucan to facilitate antifungal discontinuation in the intensive care unit. Diagn. Microbiol. Infect. Dis. 2019, 95, 162-165. [CrossRef]

57. Hall, L.; Le Febre, K.M.; Deml, S.M.; Wohlfiel, S.L.; Wengenack, N.L. Evaluation of the Yeast Traffic Light PNA FISH Probes for Identification of Candida Species from Positive Blood Cultures. J. Clin. Microbiol. 2012, 50, 1446-1448. [CrossRef] [PubMed]

58. Tasic-Otasevic, S.; Momčilović, S.; Stojanović, N.; Skvarč, M.; Rajković, K.; Arsić-Arsenijević, V. Non-culture based assays for the detection of fungal pathogens. J. Med. Mycol. 2018, 28, 236-248. [CrossRef]

59. Pancholi, P.; Carroll, K.C.; Buchan, B.W.; Chan, R.C.; Dhiman, N.; Ford, B.; Granato, P.A.; Harrington, A.T.; Hernandez, D.R.; Humphries, R.M.; et al. Multicenter Evaluation of the Accelerate PhenoTest BC Kit for Rapid Identification and Phenotypic Antimicrobial Susceptibility Testing Using Morphokinetic Cellular Analysis. J. Clin. Microbiol. 2018, 56. [CrossRef]

60. Fuchs, B.B.; Eatemadpour, S.; Martel-Foley, J.M.; Stott, S.; Toner, M.; Mylonakis, E. Rapid Isolation and Concentration of Pathogenic Fungi Using Inertial Focusing on a Chip-Based Platform. Front. Cell. Infect. Microbiol. 2019, 9, 27. [CrossRef]

61. Cooper, R.M.; Leslie, D.C.; Domanský, K.; Jain, A.; Yung, C.; Cho, M.; Workman, S.; Super, M.; Ingber, D.E. A microdevice for rapid optical detection of magnetically captured rare blood pathogens. Lab Chip 2014, 14, 182-188. [CrossRef] [PubMed]

62. Javanmard, M.; Babrzadeh, F.; Nyrén, P.; Davis, R.W. Improvement in cell capture throughput using parallel bioactivated microfluidic channels. Biomed. Microdevices 2012, 14, 625-629. [CrossRef]

63. Asghar, W.; Sher, M.; Khan, N.S.; Vyas, J.M.; Demirci, U. Microfluidic Chip for Detection of Fungal Infections. Acs Omega 2019, 4, 7474-7481. [CrossRef]

64. Lass-Flörl, C.; Cuenca-Estrella, M. Changes in the epidemiological landscape of invasive mould infections and disease. J. Antimicrob. Chemother. 2017, 72, i5-i11. [CrossRef]

65. Son, H.J.; Song, J.S.; Choi, S.; Jung, J.; Kim, M.J.; Chong, Y.P.; Lee, S.O.; Choi, S.H.; Kim, Y.S.; Woo, J.H.; et al. A Comparison of Histomorphologic Diagnosis with Culture- and Immunohistochemistry-Based Diagnosis of Invasive Aspergillosis and Mucormycosis. Infect. Dis. 2020, 52, 279-283. [CrossRef]

66. Li, Y.; Wang, H.; Zhao, Y.-P.; Xu, Y.-C.; Hsueh, P.-R. Evaluation of the Bruker Biotyper Matrix-Assisted Laser Desorption/Ionization Time-of-Flight Mass Spectrometry System for Identification of Aspergillus Species Directly from Growth on Solid Agar Media. Front. Microbiol. 2017, 8, 1209. [CrossRef]

67. Li, Y.; Wang, H.; Hou, X.; Huang, J.-J.; Wang, P.-C.; Xu, Y.-C. Identification by Matrix-Assisted Laser Desorption Ionization-Time of Flight Mass Spectrometry and Antifungal Susceptibility Testing of Non-Aspergillus Molds. Front. Microbiol. 2020, 11, 922. [CrossRef]

68. Klimek-Ochab, M.; Brzezińska-Rodak, M.; Żymańczyk-Duda, E.; Lejczak, B.; Kafarski, P. Comparative study of fungal cell disruption-Scope and limitations of the methods. Folia Microbiol. 2011, 56, 469-475. [CrossRef] [PubMed] 
69. Kidd, S.E.; Sharon, C.A.; Chen, W.M.; Catriona, L.H. A New Age in Molecular Diagnostics for Invasive Fungal Disease: Are We Ready? Front. Microbiol. 2020, 10, 2903. [CrossRef] [PubMed]

70. Gomez, C.A.; Budvytiene, I.; Zemek, A.J.; Banaei, N. Performance of Targeted Fungal Sequencing for Culture-Independent Diagnosis of Invasive Fungal Disease. Clin. Infect. Dis. 2017, 65, 2035-2041. [CrossRef] [PubMed]

71. Trubiano, J.A.; Dennison, A.M.; Morrissey, C.O.; Chua, K.Y.; Halliday, C.L.; Chen, S.C.-A.; Spelman, D. Clinical utility of panfungal polymerase chain reaction for the diagnosis of invasive fungal disease: A single center experience. Med. Mycol. 2015, 54, 138-146. [CrossRef]

72. Rickerts, V.; Khot, P.D.; Myerson, D.; Ko, D.L.; Lambrecht, E.; Fredricks, D. Comparison of quantitative real time PCR with Sequencing and ribosomal RNA-FISH for the identification of fungi in Formalin fixed, paraffin-embedded tissue specimens. Bmc Infect. Dis. 2011, 11, 202. [CrossRef]

73. Zeller, I.; Schabereiter-Gurtner, C.; Mihalits, V.; Selitsch, B.; Barousch, W.; Hirschl, A.M.; Makristathis, A.; Willinger, B. Detection of fungal pathogens by a new broad range real-time PCR assay targeting the fungal ITS2 region. J. Med. Microbiol. 2017, 66, 1383-1392. [CrossRef]

74. Donnelly, J.P.; Chen, S.C.; Kauffman, C.A.; Steinbach, W.J.; Baddley, J.W.; Verweij, P.E.; Clancy, C.J.; Wingard, J.R.; Lockhart, S.R.; Groll, A.H.; et al. Revision and Update of the Consensus Definitions of Invasive Fungal Disease from the European Organization for Research and Treatment of Cancer and the Mycoses Study Group Education and Research Consortium. Clin. Infect. Dis. 2020, 71, 1367-1376. [CrossRef] [PubMed]

75. Deurenberg, R.H.; Bathoorn, E.; Chlebowicz, M.A.; Couto, N.; Ferdous, M.; García-Cobos, S.; Kooistra-Smid, A.M.D.; Raangs, E.C.; Rosema, S.; Veloo, A.C.M.; et al. Application of next generation sequencing in clinical microbiology and infection prevention. J. Biotechnol. 2017, 243, 16-24. [CrossRef]

76. Gu, W.; Miller, S.; Chiu, C.Y. Clinical Metagenomic Next-Generation Sequencing for Pathogen Detection. Annu. Rev. Pathol. Mech. Dis. 2019, 14, 319-338. [CrossRef] [PubMed]

77. Litvintseva, A.P.; Hurst, S.; Gade, L.; Frace, M.A.; Hilsabeck, R.; Schupp, J.M.; Gillece, J.D.; Roe, C.; Smith, D.; Keim, P.; et al. Whole-Genome Analysis of Exserohilum Rostratum from an Outbreak of Fungal Meningitis and Other Infections. J. Clin. Microbiol. 2014, 52, 3216-3222. [CrossRef]

78. Etienne, K.A.; Roe, C.C.; Smith, R.M.; Vallabhaneni, S.; Duarte, C.; Escandón, P.; Castañeda, E.; Gómez, B.L.; De Bedout, C.; López, L.F.; et al. Whole-Genome Sequencing to Determine Origin of Multinational Outbreak of Sarocladium kiliense Bloodstream Infections. Emerg. Infect. Dis. 2016, 22, 476-481. [CrossRef] [PubMed]

79. Garcia-Hermoso, D.; Criscuolo, A.; Lee, S.C.; Legrand, M.; Chaouat, M.; Denis, B.; Lafaurie, M.; Rouveau, M.; Soler, C.; Schaal, J.V.; et al. Outbreak of Invasive Wound Mucormycosis in a Burn Unit Due to Multiple Strains of Mucor Circinelloides, F. Circinelloides Resolved by Whole-Genome Sequencing. mBio 2018, 9, 2. [CrossRef]

80. Hong, D.K.; Blauwkamp, T.A.; Kertesz, M.; Bercovici, S.; Truong, C.; Banaei, N. Liquid biopsy for infectious diseases: Sequencing of cell-free plasma to detect pathogen DNA in patients with invasive fungal disease. Diagn. Microbiol. Infect. Dis. 2018, 92, 210-213. [CrossRef]

81. Armstrong, A.E.; Rossoff, J.; Hollemon, D.; Hong, D.K.; Muller, W.J.; Chaudhury, S. Cell-free DNA next-generation sequencing successfully detects infectious pathogens in pediatric oncology and hematopoietic stem cell transplant patients at risk for invasive fungal disease. Pediatr. Blood Cancer 2019, 66, e27734. [CrossRef]

82. Hogan, C.A.; Yang, S.; Garner, O.B.; Green, D.A.; Gomez, C.A.; Bard, J.D.; Pinsky, B.A.; Banaei, N. Clinical Impact of Metagenomic Next-Generation Sequencing of Plasma Cell-Free DNA for the Diagnosis of Infectious Diseases: A Multicenter Retrospective Cohort Study. Clin. Infect. Dis. 2020. [CrossRef]

83. Hill, J.A.; Dalai, S.C.; Hong, D.K.; Ahmed, A.A.; Ho, C.; Hollemon, D.; Blair, L.; Maalouf, J.; Keane-Candib, J.; Stevens-Ayers, T.; et al. Liquid Biopsy for Invasive Mold Infections in Hematopoietic Cell Transplant Recipients with Pneumonia Through Next-Generation Sequencing of Microbial Cell-Free DNA in Plasma. Clin. Infect. Dis. 2020. [CrossRef] [PubMed]

84. Blauwkamp, T.A.; Thair, S.; Rosen, M.J.; Blair, L.; Lindner, M.S.; Vilfan, I.D.; Kawli, T.; Christians, F.C.; Venkatasubrahmanyam, S.; Wall, G.D.; et al. Analytical and clinical validation of a microbial cell-free DNA sequencing test for infectious disease. Nat. Microbiol. 2019, 4, 663-674. [CrossRef]

85. De Carolis, E.; Posteraro, B.; Lass-Flörl, C.; Vella, A.; Florio, A.; Torelli, R.; Girmenia, C.; Colozza, C.; Tortorano, A.; Sanguinetti, M.; et al. Species identification of Aspergillus, Fusarium and Mucorales with direct surface analysis by matrix-assisted laser desorption ionization time-of-flight mass spectrometry. Clin. Microbiol. Infect. 2012, 18, 475-484. [CrossRef]

86. Normand, A.-C.; Cassagne, C.; Gautier, M.; Becker, P.; Ranque, S.; Hendrickx, M.; Piarroux, R. Decision criteria for MALDI-TOF MS-based identification of filamentous fungi using commercial and in-house reference databases. Bmc Microbiol. 2017, 17, 1-17. [CrossRef]

87. Cameron, S.J.S.; Bolt, F.; Perdones-Montero, A.; Rickards, T.; Hardiman, K.; Abdolrasouli, A.; Burke, A.; Bodai, Z.; Karancsi, T.; Simon, D.; et al. Rapid Evaporative Ionisation Mass Spectrometry (REIMS) Provides Accurate Direct from Culture Species Identification within the Genus Candida. Sci. Rep. 2016, 6, 36788. [CrossRef]

88. Strittmatter, N.; Rebec, M.; Jones, E.A.; Golf, O.; Abdolrasouli, A.; Balog, J.; Behrends, V.; Veselkov, K.; Takats, Z. Characterization and Identification of Clinically Relevant Microorganisms Using Rapid Evaporative Ionization Mass Spectrometry. Anal. Chem. 2014, 86, 6555-6562. [CrossRef] 
89. Balog, J.; Sasi-Szabó, L.; Kinross, J.; Lewis, M.R.; Muirhead, L.J.; Veselkov, K.; Mirnezami, R.; Dezső, B.; Damjanovich, L.; Darzi, A.; et al. Intraoperative Tissue Identification Using Rapid Evaporative Ionization Mass Spectrometry. Sci. Transl. Med. 2013, 5, 194. [CrossRef]

90. Rath, P.-M.; Steinmann, J. Overview of Commercially Available PCR Assays for the Detection of Aspergillus spp. DNA in Patient Samples. Front. Microbiol. 2018, 9, 740. [CrossRef]

91. White, P.L.; Hibbitts, S.J.; Perry, M.D.; Green, J.; Stirling, E.; Woodford, L.; McNay, G.; Stevenson, R.; Barnes, R.A. Evaluation of a Commercially Developed Semiautomated PCR-Surface-Enhanced Raman Scattering Assay for Diagnosis of Invasive Fungal Disease. J. Clin. Microbiol. 2014, 52, 3536-3543. [CrossRef] [PubMed]

92. Pahlow, S.; Orasch, T.; Žukovskaja, O.; Bocklitz, T.; Haas, H.; Weber, K. Rapid detection of the aspergillosis biomarker triacetylfusarinine C using interference-enhanced Raman spectroscopy. Anal. Bioanal. Chem. 2020, 412, 6351-6360. [CrossRef]

93. Alanio, A.; Garcia-Hermoso, D.; Mercier-Delarue, S.; Lanternier, F.; Gits-Muselli, M.; Menotti, J.; Denis, B.; Bergeron, A.; Legrand, M.; Lortholary, O.; et al. Molecular identification of Mucorales in human tissues: Contribution of PCR electrospray-ionization mass spectrometry. Clin. Microbiol. Infect. 2015, 21, e1-e5. [CrossRef]

94. Husain, S.; Camargo, J.F. Invasive Aspergillosis in solid-organ transplant recipients: Guidelines from the American Society of Transplantation Infectious Diseases Community of Practice. Clin. Transpl. 2019, 33, e13544. [CrossRef]

95. Ullmann, A.; Aguado, J.; Arikan-Akdagli, S.; Denning, D.; Groll, A.; Lagrou, K.; Lass-Flörl, C.; Lewis, R.; Munoz, P.; Verweij, P.; et al. Diagnosis and management of Aspergillus diseases: Executive summary of the 2017 ESCMID-ECMM-ERS guideline. Clin. Microbiol. Infect. 2018, 24, e1-e38. [CrossRef] [PubMed]

96. Marino, C.; Rinflerch, A.; De Lederkremer, R.M. Galactofuranose antigens, a target for diagnosis of fungal infections in humans. Futur. Sci. Oa 2017, 3, 199. [CrossRef] [PubMed]

97. Kovanda, L.L.; Kolamunnage-Dona, R.; Neely, M.; Maertens, J.; Lee, M.; Hope, W.W. Pharmacodynamics of Isavuconazole for Invasive Mold Disease: Role of Galactomannan for Real-Time Monitoring of Therapeutic Response. Clin. Infect. Dis. 2017, 64, 1557-1563. [CrossRef] [PubMed]

98. Kovanda, L.L.; Desai, A.V.; Hope, W.W. Prognostic value of galactomannan: Current evidence for monitoring response to antifungal therapy in patients with invasive aspergillosis. J. Pharm. Pharm. 2017, 44, 143-151. [CrossRef]

99. Hoenigl, M.; Salzer, H.J.F.; Raggam, R.B.; Valentin, T.; Rohn, A.; Woelfler, A.; Seeber, K.; Linkesch, W.; Krause, R. Impact of galactomannan testing on the prevalence of invasive aspergillosis in patients with hematological malignancies. Med. Mycol. 2012, 50, 266-269. [CrossRef] [PubMed]

100. Agarwal, R.; Chakrabarti, A.; Shah, A.; Gupta, D.; Meis, J.F.; Guleria, R.; Moss, R.; Denning, D.W.; ABPA complicating asthma ISHAM working group. Allergic bronchopulmonary aspergillosis: Review of literature and proposal of new diagnostic and classification criteria. Clin. Exp. Allergy 2013, 43, 850-873. [CrossRef]

101. Iain, D.P.; Malcolm Richardson, M.; Denning, D.W. Antibody Testing in Aspergillosis—Quo Vadis? Med. Mycol. 2015, 53, 417-439.

102. Villalobos, A.P.-C.; Husain, S. Aspergillus in Solid Organ and Stem Cell Transplant Patients: Emerging Options for Diagnosis and Management. Emerg. Transpl. Infect. 2020, 1-32. [CrossRef]

103. Pan, Z.; Fu, M.; Zhang, J.; Zhou, H.; Fu, Y.; Zhou, J. Diagnostic Accuracy of a Novel Lateral-Flow Device in Invasive Aspergillosis: A Meta-Analysis. J. Med. Microbiol. 2015, 64, 702-707. [CrossRef]

104. Mercier, T.; Dunbar, A.; De Kort, E.A.; Schauwvlieghe, A.; Reynders, M.; Guldentops, E.; Blijlevens, N.M.A.; Vonk, A.G.; Rijnders, B.; Verweij, P.E.; et al. Lateral flow assays for diagnosing invasive pulmonary aspergillosis in adult hematology patients: A comparative multicenter study. Med. Mycol. 2020, 58, 444-452. [CrossRef]

105. White, L.P.; Price, J.S.; Posso, R.; Cutlan-Vaughan, M.; Vale, L.; Backx, M. Evaluation of the Performance of the IMMY sona Aspergillus Galactomannan Lateral Flow Assay When Testing Serum to Aid in Diagnosis of Invasive Aspergillosis. J. Clin. Microbiol. 2020, 58. [CrossRef] [PubMed]

106. Jenks, J.D.; Mehta, S.R.; Taplitz, R.; Law, N.; Reed, S.L.; Hoenigl, M. Bronchoalveolar lavage Aspergillus Galactomannan lateral flow assay versus Aspergillus-specific lateral flow device test for diagnosis of invasive pulmonary Aspergillosis in patients with hematological malignancies. J. Infect. 2019, 78, 249-259. [CrossRef] [PubMed]

107. Jenks, J.D.; Mehta, S.R.; Taplitz, R.; Aslam, S.; Reed, S.L.; Hoenigl, M. Point-of-care diagnosis of invasive aspergillosis in nonneutropenic patients: Aspergillus Galactomannan Lateral Flow Assay versus Aspergillus -specific Lateral Flow Device test in bronchoalveolar lavage. Mycoses 2018, 62, 230-236. [CrossRef] [PubMed]

108. Marr, K.A.; Datta, K.; Mehta, S.; Ostrander, D.B.; Rock, M.; Francis, J.; Feldmesser, M. Urine Antigen Detection as an Aid to Diagnose Invasive Aspergillosis. Clin. Infect. Dis. 2018, 67, 1705-1711. [CrossRef] [PubMed]

109. Heldt, S.; Hoenigl, M. Lateral Flow Assays for the Diagnosis of Invasive Aspergillosis: Current Status. Curr. Fungal Infect. Rep. 2017, 11, 45-51. [CrossRef]

110. Cruciani, M.; Mengoli, C.; Barnes, R.; Donnelly, J.P.; Loeffler, J.; Jones, B.L.; Klingspor, L.; Maertens, J.; Morton, C.O.; White, L.P. Polymerase Chain Reaction Blood Tests for the Diagnosis of Invasive Aspergillosis in Immunocompromised People. Cochrane Database Syst. Rev. 2019, 9. [CrossRef] [PubMed]

111. Avni, T.; Levy, I.; Sprecher, H.; Yahav, D.; Leibovici, L.; Paul, M. Diagnostic Accuracy of PCR Alone Compared to Galactomannan in Bronchoalveolar Lavage Fluid for Diagnosis of Invasive Pulmonary Aspergillosis: A Systematic Review. J. Clin. Microbiol. 2012, 50, 3652-3658. [CrossRef] 
112. White, L.P.; Wingard, J.R.; Bretagne, S.; Löffler, J.; Patterson, T.F.; Slavin, M.A.; Barnes, R.A.; Pappas, P.G.; Donnelly, J.P. Aspergillus Polymerase Chain Reaction: Systematic Review of Evidence for Clinical Use in Comparison with Antigen Testing. Clin. Infect. Dis. 2015, 61, 1293-1303. [CrossRef] [PubMed]

113. Schauwvlieghe, A.F.A.D.; Vonk, A.G.; Buddingh, E.P.; Hoek, R.A.S.; Dalm, V.A.; Klaassen, C.H.W.; Rijnders, B.J.A. Detection of azole-susceptible and azole-resistant Aspergillus coinfection by cyp51A PCR amplicon melting curve analysis. J. Antimicrob. Chemother. 2017, 72, 3047-3050. [CrossRef]

114. White, P.L.; Wiederhold, N.P.; Loeffler, J.; Najvar, L.K.; Melchers, W.; Herrera, M.; Bretagne, S.; Wickes, B.; Kirkpatrick, W.R.; Barnes, R.A.; et al. Comparison of Nonculture Blood-Based Tests for Diagnosing Invasive Aspergillosis in an Animal Model. J. Clin. Microbiol. 2016, 54, 960-966. [CrossRef]

115. Luong, M.-L.; Clancy, C.J.; Vadnerkar, A.; Kwak, E.J.; Silveira, F.P.; Wissel, M.C.; Grantham, K.J.; Shields, R.K.; Crespo, M.; Pilewski, J.; et al. Comparison of an Aspergillus Real-time Polymerase Chain Reaction Assay with Galactomannan Testing of Bronchoalvelolar Lavage Fluid for the Diagnosis of Invasive Pulmonary Aspergillosis in Lung Transplant Recipients. Clin. Infect. Dis. 2011, 52, 1218-1226. [CrossRef]

116. White, S.K.; Schmidt, R.L.; Walker, B.S.; Hanson, K.E. (1 $\rightarrow 3)$-Beta-D-Glucan Testing for the Detection of Invasive Fungal Infections in Immunocompromised or Critically Ill People. Cochrane Database Syst. Rev. 2020, 7, CD009833. [PubMed]

117. Leeflang, M.M.; Debets-Ossenkopp, Y.J.; Visser, C.E.; Scholten, R.J.; Hooft, L.; Bijlmer, H.A.; Reitsma, J.B.; Bossuyt, P.M. Galactomannan Detection for Invasive Aspergillosis in Immunocompromised Patients. Cochrane Database Syst. Rev. 2015. [CrossRef]

118. Bergeron, A.; Belle, A.; Sulahian, A.; Lacroix, C.; Chevret, S.; Raffoux, E.; Arnulf, B.; Socié, G.; Ribaud, P.; Tazi, A. Contribution of Galactomannan Antigen Detection in Bal to the Diagnosis of Invasive Pulmonary Aspergillosis in Patients with Hematologic Malignancies. Chest 2010, 137, 410-415. [CrossRef]

119. Hage, C.A.; Carmona, E.M.; Epelbaum, O.; Evans, S.E.; Gabe, L.M.; Haydour, Q.; Knox, K.S.; Kolls, J.K.; Murad, M.H.; Wengenack, N.L.; et al. Microbiological Laboratory Testing in the Diagnosis of Fungal Infections in Pulmonary and Critical Care Practice. An Official American Thoracic Society Clinical Practice Guideline. Am. J. Respir Crit Care Med. 2019, 200, 535-550. [CrossRef]

120. Zhou, W.; Li, H.; Zhang, Y.; Huang, M.; He, Q.; Li, P.; Zhang, F.; Shi, Y.; Su, X. Diagnostic Value of Galactomannan Antigen Test in Serum and Bronchoalveolar Lavage Fluid Samples from Patients with Nonneutropenic Invasive Pulmonary Aspergillosis. J. Clin. Microbiol 2017, 55, 2153-2161. [CrossRef]

121. Cai, X.; Ni, W.; Wei, C.; Cui, J. Diagnostic Value of the Serum Galactomannan and (1, 3)-Beta-D-Glucan Assays for Invasive Pulmonary Aspergillosis in Non-Neutropenic Patients. Intern. Med. 2014, 53, 2433-2437. [CrossRef]

122. Lengerova, M.; Racil, Z.; Hrncirova, K.; Kocmanova, I.; Volfova, P.; Ricna, D.; Bejdak, P.; Moulis, M.; Pavlovsky, Z.; Weinbergerova, B.; et al. Rapid Detection and Identification of Mucormycetes in Bronchoalveolar Lavage Samples from Immunocompromised Patients with Pulmonary Infiltrates by Use of High-Resolution Melt Analysis. J. Clin. Microbiol. 2014, 52, 2824-2828. [CrossRef]

123. Guegan, H.; Iriart, X.; Bougnoux, M.E.; Berry, A.; Robert-Gangneux, F.; Gangneux, J.P. Evaluation of Mucorgenius(R) Mucorales Pcr Assay for the Diagnosis of Pulmonary Mucormycosis. J. Infect. 2020, 81, 311-317. [CrossRef]

124. Rolle, A.-M.; Hasenberg, M.; Thornton, C.R.; Solouk-Saran, D.; Männ, L.; Weski, J.; Mäurer, A.; Fischer, E.; Spycher, P.R.; Schibli, R.; et al. ImmunoPET/MR imaging allows specific detection of Aspergillus fumigatus lung infection in vivo. Proc. Natl. Acad. Sci. USA 2016, 113, E1026-E1033. [CrossRef] [PubMed]

125. Thornton, C.R. Molecular Imaging of Invasive Pulmonary Aspergillosis Using ImmunoPET/MRI: The Future Looks Bright. Front. Microbiol. 2018, 9, 691. [CrossRef]

126. Wang, Y.; Chen, L.; Liu, X.; Cheng, D.; Liu, G.; Liu, Y.; Dou, S.; Hnatowich, D.J.; Rusckowski, M. Detection of Aspergillus fumigatus pulmonary fungal infections in mice with ${ }^{99 \mathrm{~m}}$ Tc-labeled MORF oligomers targeting ribosomal RNA. Nucl. Med. Biol. 2013, 40, 89-96. [CrossRef] [PubMed]

127. Petř́́k, M.; Franssen, G.M.; Haas, H.; Laverman, P.; Hörtnagl, C.; Schrettl, M.; Helbok, A.; Lass-Flörl, C.; Decristoforo, C. Preclinical evaluation of two ${ }^{68} \mathrm{Ga}$-siderophores as potential radiopharmaceuticals for Aspergillus fumigatus infection imaging. Eur. J. Nucl. Med. Mol. Imaging 2012, 39, 1175-1183. [CrossRef] [PubMed]

128. Petř́k M.; Haas, H.; Dobrozemsky, G.; Lass-Flörl, C.; Helbok, A.; Blatzer, M.; Dietrich, H.; Decristoforo, C. 68 Ga-Siderophores for PET Imaging of Invasive Pulmonary Aspergillosis: Proof of Principle. J. Nucl. Med. 2010, 51, 639-645. [CrossRef] [PubMed]

129. Hoenigl, M.; Orasch, T.; Faserl, K.; Prattes, J.; Loeffler, J.; Springer, J.; Gsaller, F.; Reischies, F.; Duettmann, W.; Raggam, R.B.; et al. Triacetylfusarinine C: A urine biomarker for diagnosis of invasive aspergillosis. J. Infect. 2019, 78, 150-157. [CrossRef]

130. Pfister, J.; Summer, D.; Petř́k, M.; Khoylou, M.; Lichius, A.; Kaeopookum, P.; Kochinke, L.; Orasch, T.; Haas, H.; Decristoforo, C. Hybrid Imaging of Aspergillus fumigatus Pulmonary Infection with Fluorescent, ${ }^{68}$ Ga-Labelled Siderophores. Biomolecules 2020, 10, 168. [CrossRef]

131. Skriba, A.; Pluhacek, T.; Palyzova, A.; Novy, Z.; Lemr, K.; Hajduch, M.; Petřík, M.; Havlicek, V. Early and Non-invasive Diagnosis of Aspergillosis Revealed by Infection Kinetics Monitored in a Rat Model. Front. Microbiol. 2018, 9, 2356. [CrossRef]

132. Petř́k M.; Zhai, C.; Novy, Z.; Urbánek, L.; Haas, H.; Decristoforo, C. In Vitro and In Vivo Comparison of Selected Ga-68 and Zr-89 Labelled Siderophores. Mol. Imaging Biol. 2015, 18, 344-352. [CrossRef]

133. Davies, G.; Rolle, A.M.; Maurer, A.; Spycher, P.R.; Schillinger, C.; Solouk-Saran, D.; Hasenberg, M.; Weski, J.; Fonslet, J.; Dubois, A.; et al. Towards Translational Immunopet/Mr Imaging of Invasive Pulmonary Aspergillosis: The Humanised Monoclonal Antibody Jf5 De-tects Aspergillus Lung Infections in Vivo. Theranostics 2017, 7, 3398-3414. [CrossRef] [PubMed] 
134. De Heer, K.; Van Der Schee, M.P.; Zwinderman, K.; Berk, I.A.H.V.D.; Visser, C.E.; Van Oers, R.; Sterk, P.J. Electronic Nose Technology for Detection of Invasive Pulmonary Aspergillosis in Prolonged Chemotherapy-Induced Neutropenia: A Proof-ofPrinciple Study. J. Clin. Microbiol. 2013, 51, 1490-1495. [CrossRef]

135. Koo, S.; Thomas, H.R.; Daniels, S.D.; Lynch, R.C.; Fortier, S.M.; Shea, M.M.; Rearden, P.; Comolli, J.C.; Baden, L.R.; Marty, F.M. A Breath Fungal Secondary Metabolite Signature to Diagnose Invasive Aspergillosis. Clin. Infect. Dis. 2014, 59, $1733-1740$. [CrossRef]

136. Koshy, S.; Ismail, N.; Astudillo, C.L.; Haeger, C.M.; Aloum, O.; Acharige, M.T.; Farmakiotis, D.; Baden, L.R.; Marty, F.M.; Kontoyiannis, D.P.; et al. Breath-Based Diagnosis of Invasive Mucormycosis (IM). Open Forum Infect. Dis. 2017, 4, S53-S54. [CrossRef]

137. Lewis, R.E.; Cahyame-Zuniga, L.; Leventakos, K.; Chamilos, G.; Ben-Ami, R.; Tamboli, P.; Tarrand, J.; Bodey, G.P.; Luna, M.; Kontoyiannis, D.P. Epidemiology and sites of involvement of invasive fungal infections in patients with haematological malignancies: A 20-year autopsy study. Mycoses 2013, 56, 638-645. [CrossRef] [PubMed]

138. Millon, L.; Scherer, E.; Rocchi, S.; Bellanger, A.-P. Molecular Strategies to Diagnose Mucormycosis. J. Fungi 2019, 5, 24. [CrossRef] [PubMed]

139. Scherer, E.E.; Iriart, X.; Bellanger, A.P.; Dupont, D.; Guitard, J.; Gabriel, F.; Cassaing, S.; Charpentier, E.; Guenounou, S.; Cornet, M.; et al. Quantitative PCR (qPCR) Detection of Mucorales DNA in Bronchoalveolar Lavage Fluid to Diagnose Pulmonary Mucormycosis. J. Clin. Microbiol. 2018, 56. [CrossRef]

140. Mercier, T.; Reynders, M.; Beuselinck, K.; Guldentops, E.; Maertens, J.; Lagrou, K. Serial Detection of Circulating Mucorales DNA in Invasive Mucormycosis: A Retrospective Multicenter Evaluation. J. Fungi 2019, 5, 113. [CrossRef]

141. Millon, L.; Herbrecht, R.; Grenouillet, F.; Morio, F.; Alanio, A.; Letscher-Bru, V.; Cassaing, S.; Chouaki, T.; Kauffmann-Lacroix, C.; Poirier, P.; et al. Early Diagnosis and Monitoring of Mucormycosis by Detection of Circulating DNA in Serum: Retrospective Analysis of 44 Cases Collected through the French Surveillance Network of Invasive Fungal Infections (Ressif). Clin. Microbiol. Infect. 2016, 22, e1-e8. [CrossRef]

142. Springer, J.; Lackner, M.; Ensinger, C.; Risslegger, B.; Morton, C.O.; Nachbaur, D.; Lass-Flörl, C.; Einsele, H.; Heinz, W.J.; Loeffler, J. Clinical evaluation of a Mucorales-specific real-time PCR assay in tissue and serum samples. J. Med. Microbiol. 2016, 65, 1414-1421. [CrossRef] [PubMed]

143. Caillot, D.; Valot, S.; Lafon, I.; Basmaciyan, L.; Chretien, M.L.; Sautour, M.; Million, L.; Legouge, C.; Payssot, A.; Dalle, F. Is It Time to Include Ct Reverse Halo Sign and Qpcr Targeting Mucorales in Serum to Eortc-Msg Criteria for the Diagnosis of Pulmonary Mucormycosis in Leukemia Patients. Open Forum Infect. Dis. 2016, 3, ofw190. [CrossRef] [PubMed]

144. Potenza, L.; Vallerini, D.; Barozzi, P.; Riva, G.; Forghieri, F.; Zanetti, E.; Quadrelli, C.; Candoni, A.; Maertens, J.; Rossi, A.; et al. Mucorales-specific T cells emerge in the course of invasive mucormycosis and may be used as a surrogate diagnostic marker in high-risk patients. Blood 2011, 118, 5416-5419. [CrossRef] [PubMed]

145. Potenza, L.; Vallerini, D.; Barozzi, P.; Riva, G.; Gilioli, A.; Forghieri, F.; Candoni, A.; Cesaro, S.; Quadrelli, C.; Maertens, J.; et al. Mucorales-Specific T Cells in Patients with Hematologic Malignancies. Plos One 2016, 11, e0149108. [CrossRef] [PubMed]

146. Steinbach, A.; Cornely, O.A.; Wisplinghoff, H.; Schauss, A.C.; Vehreschild, J.J.; Rybniker, J.; Hamprecht, A.; Richter, A.; Bacher, P.; Scheffold, A.; et al. Mould-reactive T cells for the diagnosis of invasive mould infection-A prospective study. Mycoses 2019, 62, 562-569. [CrossRef]

147. Burnham-Marusich, A.R.; Hubbard, B.; Kvam, A.J.; Gates-Hollingsworth, M.; Green, H.R.; Soukup, E.; Limper, A.H.; Kozel, T.R. Conservation of Mannan Synthesis in Fungi of the Zygomycota and Ascomycota Reveals a Broad Diagnostic Target. $m S p h e r e$ 2018, 3, e00094-18. [CrossRef]

148. Sato, K.; Oinuma, K.-I.; Niki, M.; Yamagoe, S.; Miyazaki, Y.; Asai, K.; Yamada, K.; Hirata, K.; Kaneko, Y.; Kakeya, H. Identification of a Novel Rhizopus-specific Antigen by Screening with a Signal Sequence Trap and Evaluation as a Possible Diagnostic Marker of Mucormycosis. Med. Mycol. 2017, 55, 713-719. [CrossRef] 